\title{
Oropharyngeal dysphagia in older persons - from pathophysiology to adequate intervention: a review and summary of an international expert meeting
}

This article was published in the following Dove Press journal:

Clinical Interventions in Aging

23 February 2016

Number of times this article has been viewed

\begin{abstract}
Rainer Wirth, ${ }^{1,2}$ Rainer
Dziewas, ${ }^{3}$ Anne Marie Beck, ${ }^{4}$

Pere Clavé, ${ }^{5}$ Shaheen Hamdy, ${ }^{6}$

Hans Juergen Heppner, ${ }^{7,8}$ Susan

Langmore, ${ }^{9}$ Andreas Herbert

Leischker, ${ }^{10}$ Rosemary Martino, 1

Petra Pluschinski, ${ }^{12}$ Alexander

Rösler, ${ }^{13}$ Reza Shaker, ${ }^{14}$ Tobias

Warnecke, ${ }^{3}$ Cornel Christian

Sieber, ${ }^{2,15}$ Dorothee Volkert ${ }^{2}$

'Department for Internal Medicine and

Geriatrics, St Marien-Hospital Borken, Borken,

Germany; ${ }^{2}$ Institute for Biomedicine of Aging,

Friedrich-Alexander-Universität Erlangen-

Nürnberg, Nürnberg, Germany; ${ }^{3}$ Department

of Neurology, University Hospital Münster.

Münster, Germany; ${ }^{4}$ Department of Nutrition and Health, Faculty of Health and Technology,

Metropolitan University College, Copenhagen,

Denmark; ${ }^{5}$ Centro de Investigación Biomédica

en Red de enfermadades Hepáticas y

Digestivas (CIBERehd), Hospital de Mataró,

Universitat Autònoma de Barcelona, Mataró,

Spain; ${ }^{6}$ Centre for Gastrointestinal Sciences,

Institute of Inflammation and Repair, University

of Manchester, Salford Royal Hospital,

Salford, UK; ${ }^{7}$ Department of Geriatrics,

Witten- Herdecke University, ${ }^{8}$ Helios Clinic

Schwelm, Schwelm, Germany; 'Department

of Speech, Language and Hearing Sciences,

Boston University School of Medicine,

Boston, MA, USA; ${ }^{10}$ Department of Geriatrics,

Alexianer Hospital Krefeld, Krefeld, Germany;

"Department of Speech-Language Pathology,

University of Toronto, Toronto, Canada;

${ }^{12}$ Department of Phoniatrics and Pediatric

Audiology, University of Marburg, Marburg,

Germany; ${ }^{13}$ Department of Geriatrics, Marien

Hospital Hamburg, Hamburg, Germany;

${ }^{14}$ Division of Gastroenterology and Hepatology,

Medical College of Wisconsin, Milwaukee,

WI, USA; ${ }^{15}$ Department of General Internal

Medicine and Geriatrics, St John of God

Hospital Regensburg, Regensburg, Germany
\end{abstract}

Correspondence: Rainer Wirth

Department of Internal Medicine and Geriatrics,

St Marien-Hospital Borken, Am Boltenhof 7 ,

D-46325 Borken, Germany

Tel +49 286I 973410

Fax +49 286I 97534II0

Email rainer.wirth@hospital-borken.de
Abstract: Oropharyngeal dysphagia (OD) is a highly prevalent and growing condition in the older population. Although OD may cause very severe complications, it is often not detected, explored, and treated. Older patients are frequently unaware of their swallowing dysfunction which is one of the reasons why the consequences of $\mathrm{OD}$, ie, aspiration, dehydration, and malnutrition, are regularly not attributed to dysphagia. Older patients are particularly vulnerable to dysphagia because multiple age-related changes increase the risk of dysphagia. Physicians in charge of older patients should be aware that malnutrition, dehydration, and pneumonia are frequently caused by (unrecognized) dysphagia. The diagnosis is particularly difficult in the case of silent aspiration. In addition to numerous screening tools, videofluoroscopy was the traditional gold standard of diagnosing OD. Recently, the fiberoptic endoscopic evaluation of swallowing is increasingly utilized because it has several advantages. Besides making a diagnosis, fiberoptic endoscopic evaluation of swallowing is applied to evaluate the effectiveness of therapeutic maneuvers and texture modification of food and liquids. In addition to swallowing training and nutritional interventions, newer rehabilitation approaches of stimulation techniques are showing promise and may significantly impact future treatment strategies.

Keywords: aspiration, dehydration, dysphagia, geriatric, malnutrition, older

\section{Introduction}

Oropharyngeal dysphagia (OD) is a clinical symptom, defined by the difficulty to effectively move the alimentary bolus from the mouth to the esophagus. Older patients are frequently unaware of their swallowing dysfunction. OD is a highly prevalent clinical condition, which affects up to $13 \%$ of the total population aged 65 years and older and $51 \%$ of institutionalized older persons. ${ }^{1}$ The prevalence of OD is highest in older patients with neurological diseases and is increasing with increasing age and frailty. ${ }^{2}$ Prevalence of OD among independently living older persons is $16 \%$ in 70 -79-year group and $33 \%$ in the $\geq 80$ years group. Prevalence of OD among older hospitalized patients is much higher. Up to $47 \%$ of frail elderly patients hospitalized for acute illness will suffer from OD. OD affects more than $50 \%$ of older nursing home residents. ${ }^{2,3}$ While many diseases with the potential to provoke dysphagia show increasing prevalence rates with increasing age, also the changes of aging per se are suggested to contribute to dysphagia. ${ }^{4,5}$ For both reasons, the worldwide prevalence of dysphagia is particularly increasing in aging societies. Although OD causes life-threatening complications, it is often not detected, explored, and treated. ${ }^{2,3}$ Many experts in the field acknowledge that OD is a major, but largely unrecognized health issue. ${ }^{2}$ The consequences of OD, ie, aspiration pneumonia, dehydration, malnutrition, and reduced quality of life, are 
devastating but often not attributed to dysphagia. The reasons for the under-recognition of dysphagia are complex. On one hand, many medical disciplines are potentially involved and their individual roles are not clearly defined. In addition, multiple professions such as nurses, physicians, speech and language pathologists, occupational therapists, and dieticians are involved and need to coordinate the process of screening, diagnosis, treatment, and monitoring. Although an eminent health care problem, the issue of OD is only marginally integrated in medical education.

This paper, which is based on an international expert meeting, aims to summarize the current knowledge about dysphagia in older persons with an interdisciplinary and interprofessional approach. Based on the available literature, but forgoing a systematic literature review, it gives a summary of the experts' view and clinical experience and points out open questions.

\section{Pathophysiology Central coordination of swallowing and pathophysiology of OD}

Swallowing is an essential part of life, whose central neural processing has increasingly been explored over the last 2 decades, applying a huge arsenal of techniques such as magnetic resonance imaging (MRI), transcranial magnetic stimulation (TMS), positron emission tomography, and magneto encephalography. Besides the well-known significance of medullary structures, involvement of a bilateral, widely distributed cortical and subcortical network has been shown. That network comprises, among others, the primary and secondary sensorimotor cortex, the premotor cortex, the insula, the cingulate gyrus, the supplementary motor area, sensorimotor integration areas, and the basal ganglia. ${ }^{6}$ Recent functional imaging studies and lesion studies suggest a hemispheric specialization for the different phases of deglutition. Predominantly, left lateralized processing of the oral phase and right hemispheric lateralization of the pharyngeal phase are assumed. ${ }^{7,8}$ Sensory input leads to a robust activation of this network. ${ }^{9}$ Conversely, disruption of afferent sensory information severely impedes the cortical control of swallowing, ultimately resulting in a decline of swallowing efficacy. ${ }^{10}$ Plastic changes of the swallowing network have been observed as physiologic reaction to different diseases and related neuroanatomical lesion locations. Obviously, stroke constitutes a convenient model to evaluate functional recovery due to spontaneous neuronal plasticity. Interestingly, stroke related dysphagia is at least in part caused by a loss of functional connectivity within the swallowing network, ${ }^{11}$ leading to a decreased activation not only in the affected but also in the undamaged hemisphere. ${ }^{12,13}$ Consequently, the often remarkable recovery of swallowing function post-stroke therefore depends on compensatory reorganization in that latter hemisphere. ${ }^{14}$ Opposed to unilateral supratentorial stroke, bilateral damage of the upper motor neuron as observed in amyotrophic lateral sclerosis renders cortical adaptation impossible and a decline in cortical activation has been found with disease progression. ${ }^{12,15}$ Lesions beyond the upper motor neuron, as seen, for example, in bulbospinal muscular atrophy featuring a selective degeneration of the second motor neuron, give rise to extensive functional reorganization within the primary sensorimotor cortex. ${ }^{16}$ Intriguing results are also achieved when studying cortical plasticity in slowly progressive neurodegenerative diseases not confined to the motor system. Thus, in Parkinson's disease (PD) adaptive cerebral changes in swallowing processing seem to compensate for deficient motor pathways. In particular, recruitment of better preserved motor loops driven by sensory afferent input maintain swallowing function until progressing neurodegeneration also exceeds beyond the means of this adaptive strategy. ${ }^{17}$ Besides disturbances of this complex network leading to neurogenic dysphagia, malignancies and other diseases of the throat may also lead to OD by affecting anatomical structures involved in the swallowing function. ${ }^{18-20}$

\section{The contribution of the upper esophageal sphincter (UES) to OD}

Among the three main components of the esophagus, namely the esophageal body and the two sphincters at its proximal and distal ends, the UES is most susceptible to the effect of aging with significant clinical consequences. The effect of age on the UES manifests mainly as a significant reduction in the cross-sectional area of the sphincter opening. This reduction is mainly due to a decrease in the maximum anteriorposterior diameter of the sphincter opening. ${ }^{21,22}$

Four components contribute to UES opening. These include: 1) UES relaxation, due to cessation of the cholinergic excitatory signals to the cricopharyngeus muscle, 2) distensibility of the UES, 3) and probably most importantly the distraction of the hyoalaryngo-cricoids-complex anteriorly and superiorly by the contraction of suprahyoid muscles, and 4) the pressure imparted from within to the wall of the UES. Abnormalities of either of these components can negatively affect the trans-sphincteric flow, resulting in reduction in pharyngo-esophageal transit, development of pharyngeal residue, and predisposing to post-deglutitive aspiration. The weakness of the suprahyoid muscles in the 
elderly seems to drive the effect of age on the UES and reduces the opening diameter.

Inadequate UES opening is a common cause of postdeglutitive residue, aspiration, and OD in a number of disorders mainly affecting older persons. OD due to abnormal UES opening is a common clinical problem after stroke, radiation therapy, and neurological deficit sustained during cardiac revascularization procedures. ${ }^{23}$ Involvement of the UES causing OD in inflammatory disorders such as Crohn's disease and inclusion body myositis has been reported. Abnormal UES opening manifests in swallowing studies as post-swallow residue, which may result in aspiration. In clinical practice this condition can be observed without a history of predisposing conditions such as stroke or radiation therapy. On manometry there will be incomplete UES relaxation and, as important, high hypopharyngeal intra-bolus pressure, ${ }^{24}$ indicating abnormal resistance to sphincteric flow which is responsible for the incomplete pharyngeal transit and its consequent piriform residue.

Theoretically OD induced by isolated UES abnormality can be: 1) primary myogenic which will respond to dilatation, 2) primary neurogenic which will respond best to myotomy or Botox injection, and 3) secondary, due to weakness of the suprahyoid opening muscles. This entity will respond to rehabilitative exercises such as the Shaker Exercise or variants of it with or without use of equipment ${ }^{23,25,26}$ or the Mendelsohn maneuver. ${ }^{27}$ Differentiation of the three categories of the UES opening abnormality with current clinical tests may be difficult since they all present with similar objective findings on fluoroscopic and manometric studies. Therefore, it seems prudent to start the therapeutic approach with the least invasive modality and adjust accordingly.

\section{Risk factors of older persons - presbyphagia}

While most of the diseases leading to OD are increasingly prevalent with advancing age, the physiologic changes of aging are also linked to the risk of dysphagia. ${ }^{1-5}$ That is why the prevalence rates are markedly increasing with the age of patients. ${ }^{28}$ Loss of muscle mass and function, a reduction of tissue elasticity, changes of the cervical spine, reduction of saliva production, impaired dental status, reduced oral and pharyngeal sensitivity, reduced olfactory and gustatory function, and reduced compensatory capacity of the aging brain are all meant to increase the susceptibility to dysphagia and may act as a precipitating factor. ${ }^{29}$ In general, the term presbyphagia is used to describe the effects of these age-related changes on the swallowing function. Even without overt disease, these changes of aging are suspected to affect all parts of the swallowing function. Herein, a prolonged oral phase, reduced tongue pressure, delayed triggering of the swallow reflex, delayed closure of the larynx, decreased swallow volume, and increased residuals and rate of penetration are described as typical changes of persons with advanced age. ${ }^{30,31}$ Some of these changes are linked to the physiologic aging process, so-called primary presbyphagia, but most factors are linked to age-related functional impairment and frailty, mostly referred to as secondary presbyphagia..$^{29}$ The most important risk factors of older persons are demonstrated in Figure 1.

Most of the features that are suggested to be associated with dysphagia are often not caused by aging per se but a mixture of aging and disease factors. For example, a dry mouth is frequently quoted as an age-dependent risk factor of dysphagia. But physiologic age-related changes of saliva production are only small and a very minor cause of xerostomia, if at all. ${ }^{32} \mathrm{~A}$ dry mouth is mostly caused by the anticholinergic side effects of medication, less frequent by a disease like Sjögren's syndrome or by radiation therapy. In healthy older individuals, Sonies et al found no differences in swallowing function despite a wide range of saliva production..$^{32}$ Even in patients with Sjögren's syndrome the capacity of saliva production was not correlated with objective measures of swallowing function, although dysphagia was perceived. ${ }^{33}$ A good documented correlation of age-related changes and swallowing function are the changes of the aging muscle. Several studies documented that a reduced mass and function of muscles involved in the swallowing process contribute to dysphagia due to aging. Feng et al have demonstrated that the volume of the geniohyoid muscle was significantly reduced in older compared to young subjects and was significantly reduced in aspirators compared to non-aspirators in otherwise healthy older subjects. ${ }^{34}$ Butler et al demonstrated that tongue strength was also significantly associated with aspiration status in older individuals..$^{35}$ In this small study, hand-gripstrength was significantly correlated with tongue strength but not significantly associated with aspiration status. An association of whole body muscle mass and function with mass and function of swallowing muscles is suspected but still needs to be confirmed. Sarcopenia is predominantly defined as a loss of muscle mass and strength or function below population based reference values. ${ }^{36}$ It is the result of aging and catabolic crises caused by disease and is closely linked with the prognosis of older persons. ${ }^{37}$ Besides falls and fractures, dysphagia may be one of the causes of the increased mortality risk of subjects with sarcopenia. 


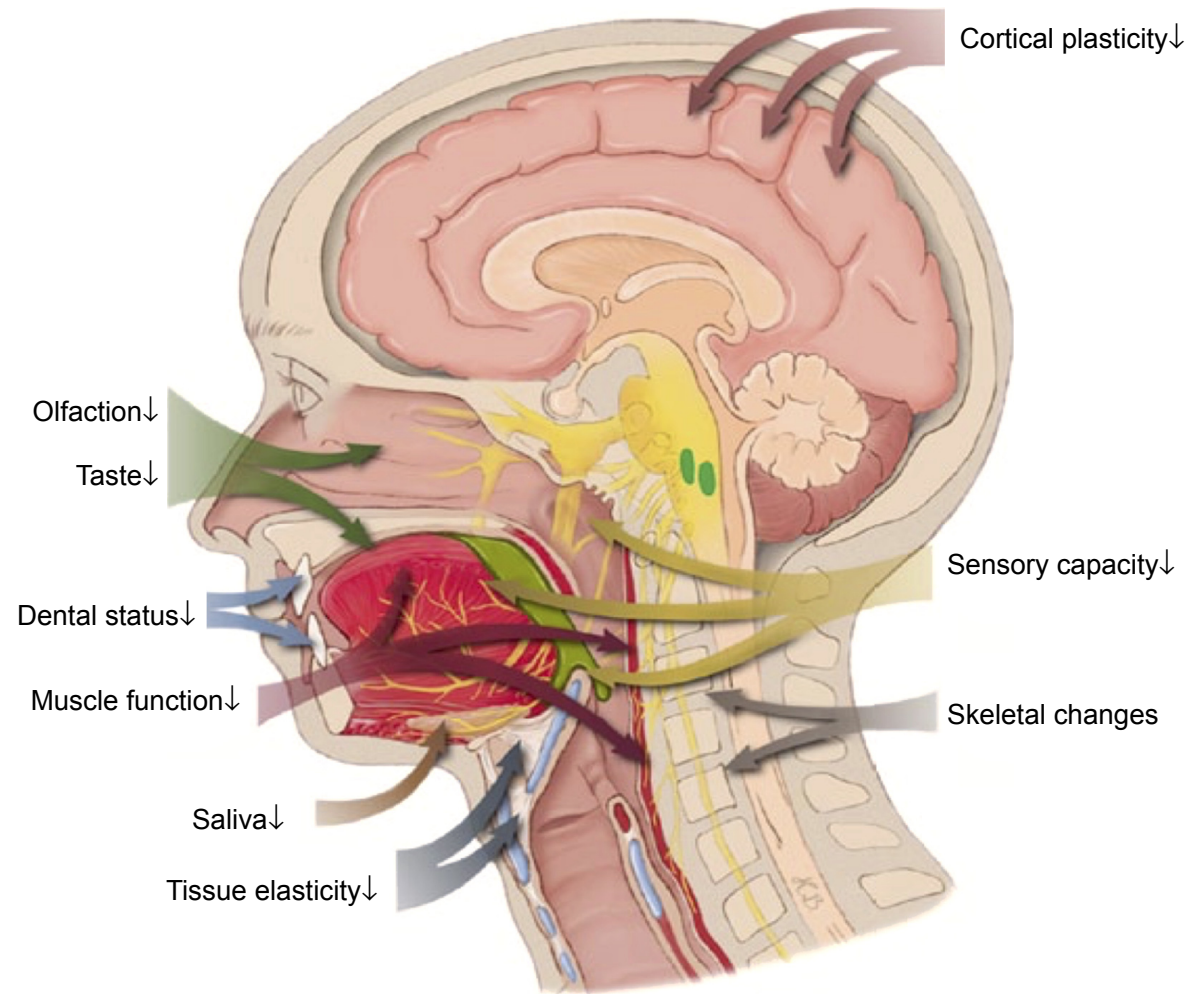

Figure I Factors associated with dysphagia in older persons.

Note: $\downarrow$ Indicates decreased function. Modified from Muhle P, Wirth R, Glahn J, Dziewas R. [Age-related changes in swallowing. Physiology and pathophysiology]. Nervenarzt. $2015 ; 86(4): 440-451 .^{29}$

Another clinically relevant factor is the side effects of medication in older patients. There are only case reports and very few studies on that issue, but given the fact that approximately $50 \%$ of older subjects are under polypharmacy ( $>4$ medicines) it is very likely that medications affecting swallowing function are frequently included. Whilst sedatives are reducing the vigilance of patients and thus increasing the risk of aspiration, opioids may specifically suppress the protective coughing reflex and neuroleptics often lead to secondary parkinsonism and impaired swallowing. ${ }^{38}$ The anticholinergic action of multiple medications on saliva production leads to a dry mouth which is linked to increased residuals in the throat and a reduced cognitive function, which itself may lead to dysphagia. Independent from this, a mild cognitive impairment per se was found to be highly associated with dysphagia risk. ${ }^{39}$

\section{Health consequences of dysphagia}

OD frequently leads to severe distress during meals, aspiration with the consequence of chronic bronchial inflammation and aspiration pneumonia, reduced food and fluid intake with the consequences of malnutrition and dehydration, and thus to reduced quality of life and increased risk of mortality. In general, aspiration is life-threatening and therefore most important from the clinician's perspective. Research from one study with qualitative methodology comparing the clinician's, caregiver's, and patient's perspectives indicates that patients may consider the psychological consequences, ie, fear, depression, embarrassment, and frustration, even more important. ${ }^{40}$

\section{Aspiration pneumonia}

There is no uniform definition of the term aspiration pneumonia and varying definitions are used. Most definitions include dysphagia as a primary component and radiological evidence of involvement of a gravity-dependent pulmonary segment is a frequent criterion. ${ }^{41-43}$

Aspiration pneumonia is the result of inhaling bacterially contaminated saliva or a foreign substance. It occurs predominantly in older patients and those with a history of swallowing difficulty. ${ }^{44}$ Prevalence data range from $6 \%$ to $53 \%$ of all pneumonias, depending on the definition of aspiration pneumonia and the study cohort. Several studies suggest that $5 \%-15 \%$ of all community-acquired pneumonias are aspiration pneumonias. ${ }^{45}$ The causes and risk factors of aspiration pneumonia are multifaceted as listed in Table $1 .{ }^{46-48}$

The most common acute complications of aspiration are infections and/or sepsis with aspiration pneumonia. ${ }^{49}$ 
Table I Causes and risk factors of aspiration pneumonia

\begin{tabular}{ll}
\hline Causes & Risk factors \\
\hline $\begin{array}{l}\text { Impaired } \\
\text { consciousness }\end{array}$ & $\begin{array}{l}\text { Drug or alcohol abuse, general anesthesia, } \\
\text { seizures, sedation, acute stroke and other } \\
\text { brain lesions, head injury } \\
\text { Increasing age, polypharmacy, functional } \\
\text { decline, poor mobility }\end{array}$ \\
Age-associated & $\begin{array}{l}\text { Esophageal stricture, esophageal diverticula, } \\
\text { gastro-esophageal reflux, oropharyngeal } \\
\text { disorders }\end{array}$ \\
latrogenic & $\begin{array}{l}\text { Adverse drug effects, adverse effects of } \\
\text { medical treatment } \\
\text { COPD, male sex, tracheostomy, tracheo- } \\
\text { Others }\end{array}$ \\
& $\begin{array}{l}\text { esophageal fistula, ventilator-associated } \\
\text { pneumonia, periodontal disease }\end{array}$ \\
\hline
\end{tabular}

However, there are also life-threatening long-term risks such as long-term inflammation of the lungs and lung abscesses.

Aspiration pneumonia often presents with nonspecific symptoms such as fever, headache, nausea, vomiting, myalgia, and confusion or only discomfort. Sometimes symptoms are more specific like cough, dyspnea, noisy breathing, chocking, or pleuritic chest pain, but aspiration pneumonia may also be silent, as shown in an autopsy study which demonstrated that in one-third of aspiration pneumonias, the pneumonia itself was unrecognized..$^{50}$ Aspiration pneumonia is typically diagnosed like any other pneumonia. Simply, the coincidence with OD, which unfortunately is often overseen, leads to the diagnosis of aspiration pneumonia. The most frequently isolated bacteria from patients with communityacquired aspiration pneumonia were Streptococcus pneumoniae, Haemophilus influenzae, Staphylococcus aureus, and Enterobacteriaceae, while Gram-negative flora were predominantly isolated in hospital-acquired cases: Klebsiella pneumoniae, Escherichia coli, Enterobacter spp., and Pseudomonas aeruginosa. ${ }^{51,52}$ In this context it is important to notice that the causative germs differ according to functional status of the patient. Patients with higher dependency in activities of daily living show more infections with Gramnegative and anaerobic pathogens. Thus, this is also typical in patients with aspiration pneumonia living in long-term care facilities. ${ }^{53,54}$ First line of treatment are antibiotics, initiated immediately after diagnosis. Similarly important, the type and severity of dysphagia should be determined and specific nutritional support as well as dysphagia therapy should be initiated, to avoid recurrent aspirations. The 30-day mortality rate from aspiration pneumonia is $21 \%$ overall and $30 \%$ in health care-associated aspiration pneumonia. ${ }^{55}$ Patients with aspiration pneumonia were older, had greater disease severity, and had more comorbidities than patients with non-aspiration pneumonia. They were more likely cared for in the intensive care unit (19\% vs $13 \%)$, had longer hospital length of stay (9 vs 7 days), and took longer to achieve clinical stability (8 vs 4 days). ${ }^{56}$ Frail elderly patients with aspiration pneumonia had a significantly increased mortality within 30 days after admission. ${ }^{57}$

\section{Malnutrition and dehydration}

It is obvious that dysphagia directly impairs the ability to eat and drink, reduces dietary intake of energy, water, and other nutrients and sooner or later will result in malnutrition and dehydration - if corrective actions are not taken. In older persons, food and fluid intake are often already reduced due to age-related changes, eg, anorexia of aging, chewing problems, or cognitive decline, and due to social, emotional, or health problems. In addition, in case of illness, dietary requirements may be increased. Moreover, neurologic diseases causing dysphagia are often accompanied by impairments decreasing the ability to eat independently, eg, arm paralysis and perception disorders following stroke, strong trembling in PD, or attention deficits and behavioral disorders in dementia. Thus, older patients suffering from dysphagia are at high risk of developing malnutrition and dehydration. For further details, please see Figure 2. Accordingly, malnutrition is widespread in the older population, and prevalence rates are increasing with decreasing health status. ${ }^{58}$ For older persons with dysphagia, a significantly increased risk of malnutrition is documented in all health care settings, ie, community-dwelling older persons, ${ }^{59}$ nursing home residents, ${ }^{60}$ geriatric patients, ${ }^{61,62}$ and specifically in stroke patients. ${ }^{63}$ Adverse effects of malnutrition, eg, increased risk of complications, delayed rehabilitation, and increased risk of mortality, are well-known, and are also very well documented in patients with dysphagia. ${ }^{61,64-70}$ Since malnutrition is accompanied by a loss of muscle mass and function, also affecting masticatory and swallowing muscles, dysphagia is self-reinforcing and may trigger the frailty process in older persons.

Dehydration increases the risk of aspiration pneumonia via xerostomia, decreased oropharyngeal cleaning, increased oropharyngeal bacterial colonization, and oropharyngeal infections. Dehydration may contribute to mental confusion, vertigo, physical weakness, fatigue, and thus also promote the frailty syndrome. ${ }^{71}$

In order to avoid or at least reduce these serious consequences, nutritional interventions are mandatory in patients with dysphagia. Primary aim of these interventions are the reduction of aspiration and the provision of adequate amounts 


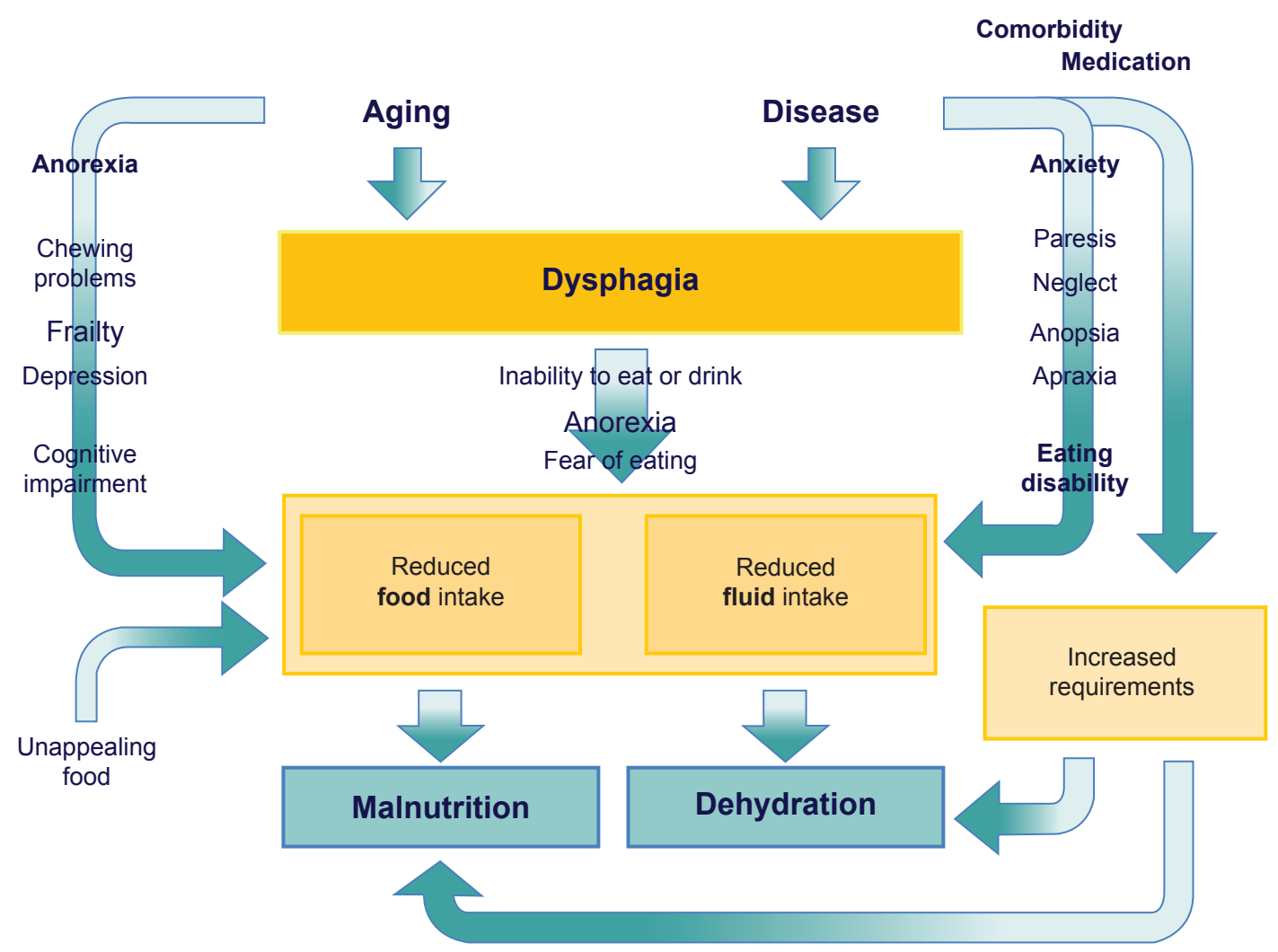

Figure 2 The role of dysphagia in the development of malnutrition and dehydration in older persons.

of energy and nutrients in order to avoid malnutrition and dehydration. As a result, the above mentioned consequences may be reduced and dysphagia therapy and rehabilitation are supported.

Generally, all kinds of nutritional support come into consideration - ranging from standard oral nutrition and texture-modified diets to complete enteral and parenteral nutrition. The kind and duration of nutrition interventions depend on type and extent of the swallowing disturbance, nutritional status, and comorbidity, and should be determined individually on the basis of a detailed assessment of the patient's current state.

Since oral nutrition may be life-threatening in case of severe dysphagia and aspiration, the consistency of foods and fluids, which can be swallowed without danger, has to be carefully examined by a swallowing specialist before starting nutritional support.

In close interdisciplinary cooperation, an individually adjusted nutritional care plan has to be developed to support safe, easy, and appealing oral consumption. Since patients with dysphagia usually do not meet their dietary requirements either by normal or by texture-modified diet, ${ }^{72,73}$ oral intake should be facilitated and increased by enrichment of meals and oral nutritional supplements. If oral food and fluid intake is insufficient or even impossible, enteral feeding is indicated. Detailed information concerning this matter can be found in special guidelines. ${ }^{74,75}$

Besides direct nutrition interventions, many older patients require nursing assistance and rehabilitative measures in order to regain the ability to eat and drink independently.

Since nutritional problems are often longstanding, continuous monitoring after hospital discharge and, if indicated, adaptation of nutritional therapy are necessary.

\section{Screening and assessment of dysphagia}

Dysphagia is assessed in one of three ways using any of the following: screening, clinical, and/or instrumental tests. These methods differ in purpose, scope, and accuracy. ${ }^{76}$ Screening tests serve to capture a brief set of dysphagia signs and symptoms to identify the likelihood of a swallowing impairment in patients otherwise not previously identified. In contrast, clinical diagnostic tests serve to capture a more comprehensive set of dysphagia signs and symptoms and therefore confirm the presence, location, and severity of a swallowing impairment. Instrumental assessment tools serve the same purpose as the clinical assessment, but go one step 
further in that these tests utilize objective technology to measure dysphagia physiology.

\section{Screening and clinical assessment}

A nurse or other clinician trained by a dysphagia expert, typically administers a screening test. ${ }^{77}$ Screening serves to identify those patients with the greatest risk of having dysphagia so that they may be referred to a dysphagia expert who will then administer a comprehensive diagnostic clinical assessment. Findings from screening provide no information about dysphagia severity or best treatment. Only findings from comprehensive testing are sufficient to direct dysphagia treatment. ${ }^{76}$ A comprehensive clinical assessment of swallowing should be considered an essential part of intervention for all patients with previously confirmed or likely dysphagia (ie, positive screening finding). There are several elements that comprise a clinical swallowing evaluation, including a comprehensive medical history, a physical exam of oral and motor function, and assessment of food intake. ${ }^{76}$ In patients with confirmed dysphagia, the re-administration of the clinical assessment serves to refine and update the course of intervention as the dysphagia ameliorates or potentially worsens over time. Alternatively, in patients who are suspected to have dysphagia from positive screening, a clinical assessment serves to confirm its presence and chart the most appropriate next steps, such as: further testing with objective instrumental swallow tests, consultation with other medical specialists, or tailored treatment.

The brief screening tests further differ from the more comprehensive diagnostic clinical tests in their psychometric accuracy. For example, a screening test aims only to identify those at greatest risk for dysphagia, thus requiring a high sensitivity. ${ }^{76}$ Sensitivity is defined as the proportion of patients with dysphagia who are correctly identified by the screening, also known as the true positive value. ${ }^{78}$ The clinical diagnostic test, in contrast, serves to validate the presence of dysphagia and to determine its severity and appropriate interventions. This comprehensive clinical assessment requires high specificity. ${ }^{76}$ Specificity is defined as the proportion of patients without dysphagia who are correctly ruled to not have dysphagia, also known as the true negative value. ${ }^{78}$ Therefore, the proper assessment of swallowing should be considered a three-step process: whereby, the screen is administered first (to identify a potential dysphagia); if screening is positive then a clinical assessment is administered to validate the presence of dysphagia and determine the best intervention; and finally if more objective information is required an instrumental assessment is administered. Unlike clinical assessment, instrumental testing is not necessary for all patients but only when there is suspicion of pharyngeal or upper esophageal stage dysphagia that cannot be sufficiently assessed by a clinical exam. ${ }^{76}$ The combination of this three-step process generates an efficient and accurate way to identify dysphagia in the clinical setting. ${ }^{79}$

Fortunately, at least in patients who have suffered a stroke, there is emerging evidence that early detection of dysphagia from screening reduces subsequent pulmonary complications, length of hospital stay, and overall health care costs. ${ }^{80}$ As a result, stroke guidelines have been developed, ${ }^{75,81-84}$ stressing the importance of early detection of dysphagia with validated screening tools. These guidelines require that trained clinicians screen individuals admitted with stroke or suspicion of stroke for dysphagia as soon as they are alert and able. A standardized tool must be used. Those patients with a positive dysphagia screen should be kept "nil by mouth" and followed up with a comprehensive assessment of swallowing within 24 hours.

In addition to the psychometric property of high sensitivity for screening tools and high specificity for clinical and instrumental diagnostic tools, all assessments also need to be reliable, valid, and feasible. ${ }^{85} \mathrm{~A}$ systematic review by Schepp et $\mathrm{al}^{86}$ aimed to identify such dysphagia screening protocols for patients with stroke. They identified and critically appraised 35 published screening protocols, of which only two met these methodological criteria - the Toronto Bedside Swallowing Screening Test (TOR-BSSTC) ${ }^{77}$ and the Barnes Jewish Hospital Stroke Dysphagia Screen. ${ }^{87}$ Recently, an update to this systematic review was performed, which expanded the scope to include all etiologies ${ }^{88}$ Although seven newly published screening tools were identified, none of the newer tools met the minimum criteria of statistical validation, ${ }^{85}$ thereby providing further support to the earlier conclusions by Schepp et al. ${ }^{86}$ The systematic review also captured recently published tools targeting comprehensive clinical or instrumental diagnostic assessment of swallowing impairment. No newer tools were identified with sufficient methodological rigor, and therefore readiness, for implementation into clinical practice. ${ }^{88}$ Across all newly identified assessments, serious methodological violations were identified relating to: patient selection based on prior knowledge of swallowing status; failure to use rater blinding during administration of the index test and/or criterion reference test; and, failure to assess inter-rater reliability for the index and/or criterion reference tests. Each of these methodological violations place a study at substantial risk for bias. For example, enrolling patients with known dysphagia and/or a control group without dysphagia 
may overestimate the diagnostic accuracy estimate of the new index test, ${ }^{85}$ and thereby introduce a bias in its favor. Also, the potential for bias in studies without blinding of both their index and criterion reference tests relates to the subjectivity of interpreting their findings, hence a likely opportunity to exaggerate the diagnostic accuracy. ${ }^{85}$ Some articles defined dysphagia narrowly according to airway safety alone without consideration of swallow efficiency. By restricting dysphagia to aspiration, milder and more "difficult-to-diagnose" levels of dysphagia may be missed also resulting in an overestimation of diagnostic accuracy. ${ }^{85}$

\section{Instrumental assessment}

\section{Videofluoroscopy Swallowing Study (VFSS)}

The Videofluoroscopy Swallowing Study (VFSS) is the traditional gold standard for diagnosis of OD. VFSS is a dynamic exploration that evaluates the safety and efficacy of deglutition, characterizes the alterations of deglutition in terms of videofluoroscopic signs, allows accurate measurement of the oropharyngeal swallow response, and helps to select and assess specific therapeutic strategies. The technique consists of swallowing boluses prepared with barium or a water-soluble contrast medium in different viscosities and recording of a radiologically-acquired video of the swallow act. Recordings are taken in the lateral and anterior-posterior view at 25 or more frames per second. VFSS can be used to assess the effect of different volumes, viscosities, and food textures; the effectiveness of compensatory maneuvers; and swallow physiology in the patient. The main videofluoroscopic signs of dysphagia are bolus penetration and aspiration, measured on the penetration aspiration scale; ${ }^{89} \mathrm{a}$ delayed or uncoordinated swallow response; impaired bolus formation and propulsion; ineffective swallow or oropharyngeal residue; and impaired opening of the UES. VFSS can determine whether aspiration occurs before, during, or after the swallow response. ${ }^{71}$ Predeglutitive aspirations are caused by impaired glossopalatal seal. Aspirations during swallowing are caused by a delay in triggering the pharyngeal swallow or impaired deglutitive airway protection (laryngeal elevation, epiglottic descent, and closure of vocal folds). Up to $40 \%$ of older patients with OD show aspirations during pharyngeal phase of swallow response, one-third without cough (silent aspirations). Impaired safety of deglutition and aspirations in older persons are mainly caused by delayed laryngeal vestibule closure. Impaired efficacy and residue are mainly related to weak tongue bolus propulsion forces and slow hyoid motion. ${ }^{30}$

Finally, VFSS can be used to select treatment for older patients with OD, as identification of VFSS signs allows patients with dysphagia to be classified into several therapeutic categories: a) patients with mild symptoms who need strategies based mainly on the reduction of volume and increase in bolus viscosity; b) patients with severe symptoms who also need changes in head posture, increased sensory input, swallowing maneuvers, and other active treatments; and c) those patients with such severe aspirations or such inefficient swallowing that they need tube feeding in addition to swallowing therapy in order to avoid respiratory complications or malnutrition..$^{71}$ It is recommended to maintain a minimal safe oral intake in these patients with the aim of rehabilitation and continued clearance of the throat, to avoid bacterial overgrowth. Increasing bolus viscosity improves the safety of swallowing in older patients demonstrated by a reduction in the prevalence of penetrations and aspirations during VFSS..$^{90}$

\section{Fiberoptic endoscopic evaluation of swallowing (FEES)}

FEES is a common, standard procedure used to evaluate patients with OD. It is often compared to the fluoroscopic procedure, which is used for the same purpose but has a very different perspective of the anatomy. First, the two procedures complement each other in many ways. Each of them is used with geriatric patients to determine whether the patient has a disordered swallow, and if present, what the pattern or nature of the problem is. Second, each of them is used to test behavioral strategies or bolus alterations to see their effect on swallowing, ie, they are considered "therapeutic" evaluations.

The FEES, as described in several publications, ${ }^{91-95}$ includes three parts. First, a preliminary assessment of the anatomy is conducted, as it relates to swallowing, secretions in the hypopharynx and larynx, movement of key structures assessed in non-swallowing tasks, including base of tongue retraction, laryngeal/arytenoid elevation, pharyngeal wall squeeze, velopharyngeal closure, vocal fold mobility, and glottis closure. During swallowing, epiglottic retroflexion and airspace closure or white-out are also assessed. The whiteout is seen as a transient white endoscopic picture during the pharyngeal contraction due to the complete reflection of the light of the endoscope. The second part of a FEES is to have the patient eat and drink various liquids and solids of varying bolus sizes and consistencies to directly observe the safety and effectiveness of swallowing. Some examiners follow a strict protocol for this portion while others customize it to the patient's needs. Variables to score include: oral preparation of the bolus (containment, efficiency of mastication, etc), lingual propulsion of the bolus and initiation of the swallow 
(speed, timing with bolus flow), and pharyngeal clearance. Pharyngeal delay time in seconds and location of bolus at initiation of the swallow are noted; penetration and aspiration are noted with the penetration aspiration scale score ${ }^{89}$ and whether aspiration occurred before, during, or after the swallow; and residue amount and location are scored. If any backflow of bolus occurred from the esophagus, this is noted.

FEES has some advantages compared to the fluoroscopy exam. It is a portable exam and can be done at bedside or in the nursing home without needing to transport and position the patient in a radiology suite; it uses real food and liquid with no added barium, and it is a better therapeutic exam because it can continue for a prolonged period, giving the examiner time to trial multiple strategies, bolus consistencies, etc (a VFSS is limited to 3-5 minutes of radiation time). Finally, FEES can be used in biofeedback mode, so the patient and family understand what is happening when they swallow and how different postures, etc, help or hurt swallowing. This leads to better compliance and speed of learning. In this regard, there was a recent study by Manor et al, using endoscopy to provide biofeedback to PD patients. Compared to the control group, the biofeedback group reduced the amount of residue significantly more. ${ }^{96}$

Older patients usually tolerate the procedure well, even those with dementia who do not understand the details of the exam. Family and other caregivers benefit from really understanding the swallowing problem and learning what interventions they can implement when feeding the patient that will help him swallow without aspirating.

FEES is unequivocally better for the severely dysphagic patient who has not eaten orally for weeks, months, or years. This is very relevant for frail, elderly patients who are in the intensive care unit or who have been very ill, since they may have less reserve muscle strength for swallowing. There are unique ways FEES can assess these patients' potential for beginning to take food by mouth. On entering the pharynx, the examiner will assess the status of secretions and the patient's response to the secretions (cough, clear throat, or no response). Movement of structures and sensory status can be directly assessed. Then, a very small amount of water or ice chips can be given to "test" their ability to swallow safely. This part of the exam often continues for 5-6 trial bolus deliveries in order to give the swallow system a chance to "wake up". We often see improved swallowing over the course of the study - enough to see potential for recovery and to guide the clinician's plan to transition the patient to eating orally again.
Are there different norms on swallowing function in older patients? The largest study to date that has generated swallowing norms for older patients was done using FEES as the evaluation tool. Butler et al assessed 76 elderly healthy volunteers 70-90 years of age. They were given a FEES and swallow variables of dwell time, residue, and aspiration were noted. ${ }^{4}$ They found that penetration was seen in $83 \%$ of the participants and aspiration in $28 \%$ of the participants. However, each participant who did penetrate or aspirate only did so on a small fraction of the total boluses swallowed (penetration on $19 \%$ of all swallows and aspiration on $3 \%$ of all swallows). There was a significant increase in frequency of penetration and aspiration with advanced age. These results suggest that aspiration increases with age, even in the healthy elderly person. Similarly, Butler et al found that the initiation of the swallow was slower in the elderly, with significantly more "spillage and dwell time" in the pharynx noted in the oldest age group. This same research group followed up a year later on 50 of the participants, including 25 who had aspirated and 25 who had not aspirated. ${ }^{97}$ There were no significant differences in their pulmonary computed tomography findings, suggesting that the aspiration experienced by these "aspirators" was benign. This trend was observed in spite of the fact that $61 \%$ of the aspiration events did not trigger a cough during the study. Finally, it is noteworthy that none of the aspiration events occurred with food, which might have been more difficult for the lungs to clear.

A second area of research with direct clinical implications for the very severely dysphagic patient focuses on secretions. Thicker secretions, a greater amount, and presence of secretions in the laryngeal vestibule all predict a more severe dysphagia. This was first reported by Murray et $\mathrm{al}^{98}$ when a small number of elderly patients were assessed. Only those with dysphagia had secretions that remained consistently in the larynx - and those with vestibular secretions had significantly more aspiration when given food or liquid to eat/ drink. Since that study, several others have noted the clinical importance and predictability of excess secretions. One of these studies done in 2012 gave 148 nursing home residents a FEES and tracked them for 3 months. ${ }^{99}$ Although only $7 \%$ showed aspiration of secretions in the FEES, secretions proved to be the only significant predictor of pneumonia.

\section{Therapeutic approaches and interventions}

The main goal of dysphagia therapy is to reduce morbidity and mortality associated with chest infections and poor nutritional status. A good swallowing therapy provides safe and adequate nutrition and hydration with minimal 
complications. It aims to recover physiologic swallowing and maintain quality of life as far as possible. Many types of treatment have been suggested for OD. Therapy of dysphagia can be divided into compensatory and rehabilitative strategies. Compensation is primarily utilized to keep patients safe when eating, whereas rehabilitation is utilized to accelerate the recovery process.

\section{Swallowing training}

Dysphagia therapy, especially in geriatrics, should be embedded in comprehensive dysphagia management. The therapeutic interventions should be established as well defined steps in a clinical pathway. Moreover, they should be planned as diagnosis related interventions which are based on the individual pathology, based on considerations of actual scientific findings about pathophysiology, quality of life, and also economic aspects. ${ }^{100,101}$ Therapeutic interventions are based on three general principles, which are consideration of: 1) main diagnosis, 2) the patient's resources and needs, and 3) the setting the patient is living and treated in.

It has been demonstrated that formalized dysphagia protocols reduce pneumonia rates in patients with acute stroke by improved detection rate of dysphagia. ${ }^{80,102}$ Moreover, inhospital mortality, prevalence of pneumonia, and tube feeding could be reduced significantly by formalized protocols comprehensively managing the process of diagnosis and treatment of OD. ${ }^{103}$ From the work provided by Carnaby et al, ${ }^{104}$ it is known that the higher the frequency of therapeutic intervention, the better the outcome for late complications, pneumonia, and the number of patients with normalized swallowing function. The three columns of functional dysphagia therapy, as formulated by Bartholome in $1999,{ }^{105}$ provide a systematic overview of therapeutic swallowing intervention strategies.

First, there are adaptive interventions, such as dietary modifications, ${ }^{106}$ whose efficiency should be validated by instrumental exam. The second column is built by compensatory strategies like clearance and postural changes as well as specific swallowing strategies. They are effective while performed during swallowing to avoid aspiration. Moreover, for some of those strategies there is evidence that they significantly influence swallowing physiology, like the chin down posture changes pressure in the hypopharyngeal structures as well as in the UES. ${ }^{107}$ For specific swallowing strategies like the effortful swallow there is evidence that even in a group of acute stroke patients it influences swallowing physiology in a way that the underlying neurological substrate is affected. The third column is represented by rehabilitative maneuvers, such as head-lifting exercise or the Mendelsohn maneuver.
In general, there is quite poor and contradictory evidence on the efficiency of specific therapeutical swallowing strategies. ${ }^{108,109}$ Most of the data provided by research were collected in acute stroke patients, only few in patients with neurodegenerative diseases. ${ }^{110}$ While working with this evidence in a geriatric setting one has to keep in mind that some of these strategies may not work or may not be applicable in multimorbid geriatric patients. The efficacy of a specific swallowing strategy should be verified under instrumental exam. To prove therapeutical effectiveness, validated outcome measurement tools like SWAL-QOL ${ }^{111}$ should be used. For an overview of the most utilized training techniques, please see Table 2.

\section{Texture modification of diet}

Texture modified food and thickened fluid have the purpose of making the swallowing process slower and thereby safer. In a number of countries there are written guidelines describing the various types of texture modified foods and thickened fluids recommended. Different consistencies have been defined for modified food (normal, soft, gratin/timbales, pureed) and for thickened fluid (normal, chocolate milk, syrup, and jelly). Most recommendations are primarily based on best practice and not on a systematic review of the available scientific evidence. Therefore, a systematic review was performed in 2010 , with the aim to seek out evidence as a basis to create guidelines that could ensure that these patients would be able to consume safe and sufficient oral nutrition as soon and as long as possible. Inclusion criteria were primarily randomized controlled trials (RCTs), systematic reviews, and meta-analyses. However, this area is sparsely examined, and studies with lower levels (eg, cohort studies) of evidence were therefore included as well. Answers to clinical questions led to the development of recommendations according to the evidence hierarchy (A indicates the highest level of recommendation). The recommendation was rated and downgraded with an asterisk (eg, B*), if the study did not fulfill all or most of the criteria in the quality assessment. Details about the systematic literature search, selection and evaluation/quality assessment of literature, and formulation of recommendations can be found in Andersen et al. ${ }^{113}$ A total of 16 studies (four systematic reviews, two cohort studies, and ten RCTs) were identified that fulfilled the inclusion criteria. ${ }^{113}$ The recommendations are related to the following health issues: reducing the risk of poor nutritional status, dehydration, and aspiration pneumonia. The risk of aspiration was only studied in test situations and therefore a recommendation was not made. With regard to deciding food and fluid for improving dietary intake and nutritional status in adults with OD the following 
Table 2 Some swallowing therapy techniques

\begin{tabular}{|c|c|c|c|}
\hline Technique & Execution (rationale) & Indication & $\begin{array}{l}\text { Limitations in geriatric } \\
\text { patients }\end{array}$ \\
\hline \multicolumn{4}{|l|}{ Maneuvers } \\
\hline Supraglottic swallow & $\begin{array}{l}\text { Breath hold, double swallow, forceful expiration } \\
\text { (closes vocal folds before and during swallow) }\end{array}$ & $\begin{array}{l}\text { Reduced/late vocal fold } \\
\text { closure }\end{array}$ & $\begin{array}{l}\text { Problematic in patients with } \\
\text { cardiovascular disease }\end{array}$ \\
\hline $\begin{array}{l}\text { Supersupraglottic } \\
\text { swallow }\end{array}$ & $\begin{array}{l}\text { Effortful breath hold, swallow, cough, swallow } \\
\text { (closes vocal folds before and during swallow) }\end{array}$ & $\begin{array}{l}\text { Reduced/late vocal fold } \\
\text { closure }\end{array}$ & $\begin{array}{l}\text { Problematic in patients with } \\
\text { cardiovascular disease }\end{array}$ \\
\hline Effortful swallow & $\begin{array}{l}\text { Effortful tongue action (increases posterior } \\
\text { motion of tongue base) }\end{array}$ & $\begin{array}{l}\text { Poor posterior tongue } \\
\text { base motion }\end{array}$ & $\begin{array}{l}\text { May cause fatigue of } \\
\text { swallowing }\end{array}$ \\
\hline Mendelsohn maneuver & $\begin{array}{l}\text { Prolong hyoid excursion guided by manual } \\
\text { palpation (prolongs upper esophageal sphincter } \\
\text { opening) }\end{array}$ & $\begin{array}{l}\text { Poor pharyngeal } \\
\text { clearance and laryngeal } \\
\text { movement }\end{array}$ & $\begin{array}{l}\text { May cause fatigue of } \\
\text { swallowing }\end{array}$ \\
\hline \multicolumn{4}{|l|}{ Postural adjustments } \\
\hline \multirow[t]{2}{*}{ Head tilt } & $\begin{array}{l}\text { Head tilt posteriorly at swallow initiation } \\
\text { (gravity clears oral cavity) }\end{array}$ & Poor tongue control & $\begin{array}{l}\text { Increases aspiration risk in } \\
\text { most older subjects }\end{array}$ \\
\hline & $\begin{array}{l}\text { Head tilt laterally to unaffected side (directs } \\
\text { bolus down stronger side) }\end{array}$ & $\begin{array}{l}\text { Unilateral pharyngeal } \\
\text { weakness }\end{array}$ & $\begin{array}{l}\text { May have limitations in patients } \\
\text { with cervical spine disease }\end{array}$ \\
\hline Chin tuck & $\begin{array}{l}\text { Chin down (displaces tongue base and epiglottis } \\
\text { posteriorly) }\end{array}$ & $\begin{array}{l}\text { Delayed pharyngeal } \\
\text { swallow response }\end{array}$ & $\begin{array}{l}\text { May have limitations in patients } \\
\text { with cervical spine disease }\end{array}$ \\
\hline Head rotation & $\begin{array}{l}\text { Rotate head to affected side (isolates damaged } \\
\text { side from bolus path) }\end{array}$ & $\begin{array}{l}\text { Unilateral pharyngeal } \\
\text { weakness }\end{array}$ & $\begin{array}{l}\text { May have limitations in patients } \\
\text { with cervical spine disease }\end{array}$ \\
\hline \multicolumn{4}{|l|}{ Facilitatory techniques } \\
\hline Thermal stimulation & Cold tactile stimulation to anterior faucial pillar & $\begin{array}{l}\text { Delayed/absent swallow } \\
\text { response }\end{array}$ & $\begin{array}{l}\text { Poor evidence, especially in } \\
\text { stroke patients }\end{array}$ \\
\hline Gustatory stimulation & $\begin{array}{l}\text { Sour or spicy bolus, capsaicin (facilitates } \\
\text { swallow response) }\end{array}$ & $\begin{array}{l}\text { Reduced oral sensitivity, } \\
\text { delayed/absent swallow } \\
\text { response }\end{array}$ & Promising approach \\
\hline \multicolumn{4}{|c|}{ Strengthening exercises } \\
\hline Shaker exercise & $\begin{array}{l}\text { Repeated head lifting while lying (strengthening } \\
\text { of neck and laryngeal muscles) }\end{array}$ & $\begin{array}{l}\text { Enhanced opening of } \\
\text { the upper esophageal } \\
\text { sphincter }\end{array}$ & $\begin{array}{l}\text { May have limitations in patients } \\
\text { with cervical spine disease; the } \\
\text { suggested intensity may not be } \\
\text { feasible for geriatric patients }\end{array}$ \\
\hline
\end{tabular}

Notes: Adapted from Gastroenterology, Volume II6/Edition 2, Cook IJ, Kahrilas PJ, AGA technical review on management of oropharyngeal dysphagia, Pages 455-478, Copyright 1999, with permission from Elsevier. ${ }^{112}$

was recommended: specially made and nutritionally enriched texture modified food (pureed and minced) and thickened fluid (nectar, honey, and pudding consistency) and optional courses are recommended for elderly persons with chronic dysphagia $\left(\mathrm{B}^{*}\right)$. Chin down procedure and thin fluid should be first choice rather than thickened fluid in cases of chronic dysphagia (A). In the acute phase individual counseling with a follow-up, adjustment of the consistency of texture modified food and thickened fluid should be provided (A).

Since there are only a few, high-quality studies, the evidence in favor of texture modified foods and thickened fluids, as being effective in preventing or reducing the impact of dysphagia is not strong. More studies are needed to show whether texture modified foods and thickened fluids are effective in the management of chronic and acute dysphagia. When planning these, one important aspect to consider is the patient's preference for texture modified food and/or thickened fluid compared to ordinary food. Even though this aspect was not included in the recommendations, the literature search identified studies, which proved that the patients did not prefer this type of food.

One major problem is the lack of consistency in terminology when naming different textures for texture modified food and thickened fluid in different countries. ${ }^{106}$ This made it very difficult to assess what patients had actually eaten in the included studies, and also makes it difficult to turn the recommendations into practical guidelines. Another problem is the lack of awareness of the existence of dysphagia. Apparently $60 \%-87 \%$ of residents in nursing homes have feeding difficulties, but eg, in Danish nursing homes, texture modified food is only offered to a limited number of patients. ${ }^{114}$ At present, there is international work going on in relation to standardization of the terminology. ${ }^{106}$ This should be followed by research in relation to early discovery of the problem, and not least on work in order to increase the sensory properties (eg, taste, texture, and appearance) of the texture modified menus. ${ }^{114}$ 


\section{Technical methods}

Although both compensatory and rehabilitation techniques play important roles in the recovery of swallowing function, most patients still rely on compensatory techniques before they are transferred to rehabilitation. ${ }^{115}$

\section{Peripheral stimulation}

A variety of oral stimulation techniques have been used as a part of therapeutic swallowing procedures; however, evidence of their efficacy in treatment remains controversial. There are some simple techniques that have been used in dysphagia patients such as increased pressure on the tongue by a spoon during feeding or using a sour bolus (containing lemon juice) to stimulate swallowing. ${ }^{116}$ Also, a special therapeutic program called deep pharyngeal neuromuscular stimulation has been used to improve pharyngeal swallowing. It concentrates on the stimulation of three sites with frozen lemon-glycerin swabs. These sites are:

1) The taste buds of bitter and base of tongue - to improve tongue retraction.

2) Soft palate - to improve palate elevation.

3) The superior and medial pharyngeal constrictor muscles to improve pharyngeal peristalsis movement and opening of the UES.

Thermal tactile stimulation (TTS) technique to the area in the oral cavity which contains the sensory receptors involved in triggering the pharyngeal swallow is used in many research studies. ${ }^{117}$ Cold is the best stimulus to evoke swallowing. ${ }^{118}$ TTS can be used to increase sensory awareness in the mouth before swallowing and to reduce delay between oral and pharyngeal phases (increase swallowing speed). According to de Lama Lazzara et al, ${ }^{119}$ swallowing is improved in patients with neurological diseases after thermal stimulation which sensitizes the base of the anterior faucial arches with a cold stimulus; however, a mixed population was included in this study and the limited reported data caused difficulty in the interpretations. Another study has reported that swallow improvement has occurred with repeat sensitization. ${ }^{120}$ Another study investigated the relationship between different intensities of TTS and reduced pharyngeal delay time. It demonstrated that no specific intensity of TTS was recognized as the most therapeutic. ${ }^{120}$ Power et al ${ }^{121}$ demonstrated that the cortical motor excitability for pharyngeal swallowing is inhibited, as recorded by electromyography, following sensory stimulation of the anterior faucial pillar to the focal TMS of the pre-central cortex. ${ }^{121}$ Freed et al ${ }^{122}$ conducted a study which aimed to compare the efficacy of surface electrical stimulation and TTS. Although an improvement in swallowing score was found in both groups, the swallowing score for the group treated with electrical stimulation was higher than the other group.

More recently, Rofes et al ${ }^{123}$ assessed the effects of capsaicinoids added to liquid boluses in older patients with OD. This study found that the addition of capsaicin to boluses enhanced the protective mechanisms for swallowing and improved timings - the long-term effects of this form of stimulation was not assessed but the mechanism of action is thought to relate to the effects of capsaicin on substance $\mathrm{P}$ and its effects on airway sensitivity. Fraser et al ${ }^{124}$ conducted a study which aimed to investigate the effects of pharyngeal electrical stimulation (PES) in healthy individuals with TMS and in stroke patients. They found that motor cortex excitability could be achieved at specific parameters. This study was followed by another study, which included 16 dysphagic stroke patients, six of them received sham stimulation and ten patients received $5 \mathrm{~Hz}$ of PES for 10 minutes. The outcome of this study was a $30 \%$ reduction in aspiration in the intervention group, whereas there was no change in aspiration for the sham group. This was followed up by Jayaskeran et al, who completed a dose response and small RCT of PES in 28 acute dysphagic stroke patients and also found an improvement in safe swallowing at 2 weeks in the active group alongside better feeding parameters and short length of stay in hospital by a median of 5 days compared to the sham group. ${ }^{125}$ Whether this approach can be transferred to elderly patients with dysphagia is as yet undetermined.

\section{TMS}

TMS is a safe and noninvasive technique capable of providing information about the neurophysiological properties of a target system and has been used successfully to study swallowing. ${ }^{126}$ Since its advent in 1985 , the rapid expansion of this technique has led to the development of newer devices that are now able to deliver repetitive trains of TMS (rTMS), thereby opening up new perspectives for the use of magnetic stimulation not only for functional assessment purposes but also for treatment (or brain conditioning). Both ipsilesional high frequency and contralesional low frequency rTMS have been shown to generate beneficial effects in the acute and chronic stroke brain. ${ }^{127}$ With respect to swallowing, the pharyngeal motor cortex appears to be specifically responsive to rTMS. In more recent literature, the use of rTMS has been explored in the treatment of dysphagia after stroke by several authors. ${ }^{128-130}$ In the first study by Khedr et al, ${ }^{128}$ excitatory $3 \mathrm{~Hz}$ rTMS ( 300 pulses at $120 \%$ first dorsal interosseous motor threshold) was performed for 10 minutes per day for 5 consecutive days on 26 unilateral hemispheric 
stroke patients with swallowing problems. Stimulation was delivered to the affected hemisphere, and according to the authors, resulted in a bilateral increase in brain excitability, 1 and 2 months after treatment, with an associated improvement in the symptoms and signs of dysphagia. The second study by Verin and Leroi ${ }^{129}$ attempted to decrease transcallosal inhibition between mylohyoid primary motor cortices by using an inhibitory $1 \mathrm{~Hz}$ rTMS paradigm. The authors applied 20 minutes of $1 \mathrm{~Hz}$ rTMS for 5 consecutive days to the healthy (unaffected) hemisphere of seven chronic dysphagic stroke patients (6 months post-stroke) and assessed swallowing using videofluoroscopy. The study resulted in a very modest decrease in the behavioral markers for swallowing impairment (aspiration-penetration scores) and in swallow reaction times. However, there was no control arm for the study against which comparisons could be made. It would be interesting to speculate if rTMS could be used to enhance swallowing in the geriatric population.

\section{Transcranial direct current stimulation (tDCS)}

tDCS is a neurorehabilitation technique in which a weak electric current $(\sim 1-2 \mathrm{~mA})$ is passed over the brain. The effects are dependent on the combination of parameters such as the current strength, duration of stimulation, and electrode montage. ${ }^{131}$ It appears to be both safe and well tolerated. As with TMS, the effects of tDCS have also been investigated in a dysphagic (stroke) population, but again the results are inconclusive when all studies are taken together. Similar to previous studies in healthy swallowing, ${ }^{132}$ researchers have used different neurostimulation parameters for their studies in patients, without clear rationale for the dosage of the neurostimulation approach. A single-blinded RCT with 20 stroke patients randomized to either anodal stimulation of ipsilesional or sham stimulation showed beneficial functional outcomes, when used as an adjunct to traditional swallowing therapy. ${ }^{133}$ The parameters in this trial were again different to the parameters used in earlier case-controlled studies in patients (ie, affected vs unaffected). ${ }^{134,135}$ Therefore, no direct conclusions can be reported for the utilization of this technique; however, results look promising and we are looking forward to some additional results for the optimal dosage and parameters in older patients with OD.

\section{Dysphagia in special situations} Tube feeding - when, how, and for whom? When dysphagia is so severe that the nutritional demands cannot be covered orally, artificial nutrition has to be considered. The individual indication for such an invasive procedure depends on the extent of the gap between nutritional demands and actual intake and on the patient's general prognosis. Unfortunately, the extent and duration of undernutrition which may be tolerable without disadvantages for the patient's prognosis is still unstudied and therefore unclear. Based on externally consented expert opinion, recent guidelines recommend tube feeding for geriatric patients if no nutritional intake is possible for a period longer than 3 days or if oral nutritional intake is insufficient $(<50 \%$ of demands) for longer than 10 days. ${ }^{136}$ It is also recommended that each decision has to be made on an individual basis, taking patients' prognosis and preferences into account.

Artificial nutrition may be supplied via the parenteral route, the enteral route, or a combination of both. In general, the enteral route is preferred unless contraindicated, because of a lower rate of septic complications and costeffectiveness. ${ }^{75,137,138}$ The gastric access via a nasogastric feeding tube (NGT) or a percutaneous endoscopic gastrostomy (PEG) is recommended as standard. ${ }^{75}$ Only in rare exceptions a jejunal position of the tube may be advantageous. In comparison of NGT and PEG, a Cochrane review including studies with patients suffering from nonsurgical diseases showed no difference in mortality, complications, and risk of developing pneumonia. However, there were fewer intervention failures in the PEG group when compared with the nasogastric group. ${ }^{139}$ Another systematic review including trials on patients with non-stroke related dysphagia showed no significant difference in the risk of pneumonia and overall complications between PEG and nasogastric feeding. ${ }^{140}$ According to a review of studies in patients with head and neck cancer there was also no difference in disease free survival and weight maintenance between NGT and PEG. However, patients nourished via nasogastric tube had an increased rate of tube dislodgement. On the other hand, patients with PEG took longer to return to normal diet when compared to the NGT group. ${ }^{141}$ Fortunately, in many patients with acute stroke, dysphagia improves during the first weeks after stroke. Therefore, the preferred route of feeding in patients with acute stroke is different from patients suffering from chronic diseases causing persisting dysphagia and nasogastric feeding is recommended during the first weeks after stroke. ${ }^{75,142}$ The FOOD-trial is the only RCT comparing nasogastric tube feeding with PEG in a large number of patients with acute stroke. ${ }^{143}$ Patients with severe dysphagia were randomized within 1 week into PEG and NGT groups. There was no difference in mortality between the two groups. However, patients fed with a nasogastric tube had a better outcome: after 6 months 18.9\% had a 
Modified Rankin Scale score of 0-3 compared to $11.1 \%$ in the PEG group $(P=0.05)$. In the follow-up after 6 months, $38.4 \%$ had normal oral intake compared with only $29.0 \%$ in the PEG group and $13.9 \%$ were still fed via NGT compared to $23.9 \%$ in the PEG group. In the long term, feeding via PEG is associated with fewer treatment failures, higher feed delivery, and fewer gastrointestinal bleedings. ${ }^{144}$ Therefore, if enteral feeding is likely to be needed for a longer period of time ( $>28$ days), a PEG should be placed in a stable clinical phase (after 14-28 days). If a nasogastric tube is rejected or not tolerated by the patient and if artificial nutrition will probably be necessary for more than 14 days, early placement of a PEG should be considered. In case of repeated tube dislodgement a nasal bridle (nasal loop) is an alternative. ${ }^{145}$ Nasogastric tube feeding does not relevantly interfere with swallow training. Therefore, dysphagia therapy shall start as early as possible in tube fed patients as well. The majority of conscious dysphagic patients with tube feeding should have additional oral intake, according to the kind and severity of dysphagia. ${ }^{75}$ As stated earlier, many stroke patients regain swallowing function during the first days and weeks. Positive predictors of recovery of functional swallowing after a stroke are hemorrhagic stroke, younger age, and left-sided stroke. ${ }^{146}$ Even during the first 6 months, improvement of swallowing is likely. It is therefore important to repeat assessment of the swallowing function at regular intervals.

After Alzheimer's disease (AD), PD is the neurodegenerative disease second most associated with severe dysphagia (see the following section). Malnutrition ${ }^{147,148}$ and aspiration pneumonia $^{149}$ are highly prevalent in this disease and some of these patients with advanced disease may need tube feeding. However, the indication and effects of tube feeding in this disease are not yet studied. The most common indication for the insertion of a feeding tube seems to be primarily the safe and time-controlled provision of medication, also in the form of continuous duodenal application of dopamine in patients with severe motor fluctuations. ${ }^{150}$ In both cases the tube can also be used for nutrition.

All patients with amyotrophic lateral sclerosis suffer from severe dysphagia and malnutrition at a certain stage of the disease, even very early in the bulbar variant of the disease. Tube feeding is largely supplied in these patients due to evidence from nonrandomized trials. If indicated, PEG-insertion is recommended to be performed before severe breathing problems occur. ${ }^{151}$

\section{Dysphagia in dementia}

Dementia has a prevalence of approximately $30 \%$ at the age of 80 years and over. Within the course of a dementing illness, most patients develop dysphagia. Dysphagia is one of the main risk factors for pneumonia and, in fact, patients with dementia die from pneumonia more frequently than patients without dementia. In AD, eating behavior in general seems to change early on in the disease: patients need self-feeding cues and direct assistance while eating. ${ }^{152}$ Patients with mild AD showed reduced blood oxygenation level dependent signals in many areas of the cortical swallowing network. ${ }^{153}$ With disease progression, oral transport is prolonged and the rate of patients showing aspiration increases. ${ }^{154}$ To what extent apraxia and orotactile agnosia account for dysphagia in AD is not known. There is a need for studies on cognition and dysphagia in patients with AD. There are very few studies about dysphagia in vascular dementia (VaD). The presence and extent of dysphagia depend on the localization of the vascular lesions. It is known from an MRI study in older adults without dementia that white matter lesion load in MRI correlates with swallowing duration. ${ }^{155}$ In a study comparing patients with $\mathrm{AD}$ to patients with $\mathrm{VaD}$, patients with vascular disease were more impaired in bolus formation and hyolaryngeal excursion. $\mathrm{VaD}$ patients showed a higher percentage of silent aspirations. The authors recommend focusing on motor exercises in dysphagia therapy of $\mathrm{VaD}$ patients. $^{154}$

In patients with Lewy-body disease, dysphagia, especially aspiration, seems to play an important role in limited prognosis of these patients. About one-third showed dysphagia in a study using FEES. ${ }^{156}$ Patients with frontotemporal dementia are characterized by a more compulsive eating pattern, large bolus sizes, and a longer leaking time during mastication. $^{157}$

Treatment of dysphagia in dementia is difficult, because patients with moderate to severe disease cannot follow the instructions precisely and have difficulties to transfer knowledge to daily life. Upright position, oral hygiene, and intact vigilance should be required before eating. Inserting a PEG does not prevent aspiration pneumonia in patients with severe dementia. In addition, it does not improve the course of the disease and is therefore not recommended in advanced dementia. ${ }^{74}$

In a small crossover study, passive cervical spine mobilization was able to increase the maximum swallow volume in patients with severe dementia, possibly due to a reduction in paratonic rigidity. ${ }^{158}$ In a huge multicenter trial, Logemann et al examined the short- and long-term effects of either a chin down posture or thickened liquids. ${ }^{159,160}$ All patients had been aspirating liquids in a videofluoroscopic study of swallowing (VFSS) before intervention. Fifty-five percent of the demented patients still aspirated on all three 
interventions, while $20 \%$ did not aspirate at all. Patients showed less aspiration with honey-thickened liquids, followed by nectar-thickened liquids, followed by chin down posture intervention. However, the personal preferences were different, and the possible benefit from one of the interventions showed individual patterns with the chin down maneuver being more effective in patients $>80$ years. On the long term, the pneumonia incidence in these patients was lower than expected (11\%), showing no advantage of any intervention. ${ }^{159,160}$

Taken together, dysphagia in dementia is common. Approximately $35 \%$ of an unselected group of dementia patients show signs of liquid aspiration. Dysphagia progresses with increasing cognitive impairment. ${ }^{161}$ Therapy should start early and should take the cognitive aspects of eating into account. Adaptation of meal consistencies can be recommended if accepted by the patient and caregiver.

\section{Dysphagia in PD}

PD has a prevalence of approximately $3 \%$ in the age group of 80 years and older. ${ }^{162}$ Approximately $80 \%$ of all patients with PD experience dysphagia at some stage of the disease. ${ }^{163}$ More than half of the subjectively asymptomatic PD patients already show signs of oropharyngeal swallowing dysfunction when assessed by objective instrumental tools. ${ }^{164}$ The average latency from first PD symptoms to severe dysphagia is 130 months. ${ }^{165}$ The most useful predictors of relevant dysphagia in PD are a Hoehn and Yahr stage $>3$, drooling, weight loss or body mass index $<20 \mathrm{~kg} / \mathrm{m}^{2},{ }^{166}$ and dementia in PD. ${ }^{167}$ There are mainly two specific questionnaires validated for the detection of dysphagia in PD: the Swallowing Disturbance Questionnaire for Parkinson's disease patients ${ }^{164}$ with 15 questions and the Munich Dysphagia Test for Parkinson's disease ${ }^{168}$ with 26 questions. The $50 \mathrm{~mL}$ Water Swallowing Test is neither reproducible nor predictive for severe OD in PD. ${ }^{166}$ Therefore, a modified water test assessing maximum swallowing volume is recommended for screening purposes. In clinically unclear cases instrumental methods such as FEES or VFSS should be applied to evaluate the exact nature and severity of dysphagia in PD. ${ }^{169}$ The most frequent symptoms of OD in PD are listed in Table 3.

No general recommendation for treatment approaches to OD can be given. The adequate selection of techniques depends on the individual pattern of dysphagia in each patient. Adequate therapy may be thermal-tactile stimulation and compensatory maneuvers such as effortful swallowing. In general, thickened liquids have been shown to be more effective in reducing the amount of liquid aspiration
Table 3 Patterns of oropharyngeal dysphagia in Parkinson's disease

\begin{tabular}{ll}
\hline $\begin{array}{l}\text { Phase of } \\
\text { swallowing }\end{array}$ & Frequent findings \\
\hline Oral & $\begin{array}{l}\text { Repetitive pump movements of the tongue } \\
\text { Oral residue } \\
\end{array}$ \\
& $\begin{array}{l}\text { Premature spillage } \\
\text { Piecemeal deglutition }\end{array}$ \\
Pharyngeal & $\begin{array}{l}\text { Residue in valleculae and pyriform sinuses } \\
\text { Aspiration in } 50 \% \text { of dysphagic patients }\end{array}$ \\
& Somatosensory deficits \\
& Reduced spontaneous swallow (48 vs 7I per hour) \\
& Hypomotility \\
Esophageal & Spasms \\
& Multiple contractions \\
\hline
\end{tabular}

Note: Data from Warnecke. ${ }^{170}$

compared to chin tuck maneuver. ${ }^{159}$ The Lee Silverman Voice Treatment $\left(\right.$ LSVT $\left.^{\circledR}\right)$ may improve PD dysphagia, but data are rather limited. ${ }^{171}$ Expiratory muscle strength training improved laryngeal elevation and reduced severity of aspiration events in an RCT. ${ }^{172}$ A rather new approach to treatment is video-assisted swallowing therapy for patients with PD using FEES videos of the swallowing act for biofeedback purposes during a treatment session. ${ }^{96}$ In an RCT, PD patients demonstrated a significantly greater reduction in food residues in the pharynx and there was significant group improvement in some parameters of the quality of life, quality of care, and pleasure of eating scales compared to the control group. In addition, particularly in PD patients with fluctuating dysphagia, an individual assessment of levodopa responsiveness of swallowing function may be useful. ${ }^{173,174}$

\section{Conclusion and perspective}

OD is a greatly unrecognized syndrome in older persons with serious health consequences. Accordingly, it is insufficiently studied and the evidence for interventions is still weak. On the other hand, the knowledge about the (patho) physiology of swallowing has increased enormously, building a good basis for more research on the efficacy of presently available, and development of new interventions.

The challenge of the future is to increase the recognition and visibility of OD as an important clinical syndrome and convince stakeholders of the impact of adequate treatment. In particular, the development and validation of specific interventions for older persons, the systematic investigation of side effects of medications on the swallowing physiology, and establishing the effect of sarcopenia on swallowing function have the potential to improve the situation and prognosis in this fragile patient group. 


\section{Acknowledgments}

This article is the summary of an international expert meeting, held from April 9-11, 2015 in Biedenkopf, Germany. The meeting was generously supported by the Banssfoundation, which covered the travel expenses and lodging of all experts. We gratefully thank the Banss-foundation for this unique support. Further, we acknowledge support by Deutsche Forschungsgemeinschaft and Friedrich-AlexanderUniversität Erlangen-Nürnberg (FAU) within the funding programme Open Access Publishing.

\section{Disclosure}

The authors have no conflicts of interest to disclose.

\section{References}

1. Cabre M, Serra-Prat M, Palomera E, Almirall J, Pallares R, Clave P. Prevalence and prognostic implications of dysphagia in elderly patients with pneumonia. Age and ageing. 2010;39(1):39-45.

2. Clave P, Rofes L, Carrion S, et al. Pathophysiology, relevance and natural history of oropharyngeal dysphagia among older people. Nestle Nutr Inst Workshop Ser. 2012;72:57-66.

3. Clave P, Shaker R. Dysphagia: current reality and scope of the problem. Nat Rev Gastroenterol Hepatol. 2015;12(5):259-270.

4. Butler SG, Stuart A, Leng X, Rees C, Williamson J, Kritchevsky SB. Factors influencing aspiration during swallowing in healthy older adults. Laryngoscope. 2010;120(11):2147-2152.

5. Butler SG, Maslan J, Stuart A, et al. Factors influencing bolus dwell times in healthy older adults assessed endoscopically. Laryngoscope. 2011;121(12):2526-2534.

6. Leopold NA, Daniels SK. Supranuclear control of swallowing. Dysphagia. 2010;25(3):250-257.

7. Teismann IK, Dziewas R, Steinstraeter O, Pantev C. Time-dependent hemispheric shift of the cortical control of volitional swallowing. Hum Brain Mapp. 2009;30(1):92-100.

8. Suntrup S, Kemmling A, Warnecke T, et al. The impact of lesion location on dysphagia incidence, pattern and complications in acute stroke. Part 1: dysphagia incidence, severity and aspiration. Eur J Neurol. 2015; 22(5):832-838.

9. Lowell SY, Poletto CJ, Knorr-Chung BR, Reynolds RC, Simonyan K, Ludlow CL. Sensory stimulation activates both motor and sensory components of the swallowing system. Neuroimage. 2008;42(1): 285-295.

10. Teismann IK, Steinstraeter O, Stoeckigt K, et al. Functional oropharyngeal sensory disruption interferes with the cortical control of swallowing. BMC Neurosci. 2007;8:62.

11. Li S, Ma Z, Tu S, et al. Altered resting-state functional and white matter tract connectivity in stroke patients with dysphagia. Neurorehabil Neural Repair. 2014;28(3):260-272.

12. Teismann I, Warnecke T, Suntrup S, et al. Cortical processing of swallowing in ALS patients with progressive dysphagia - a magnetoencephalographic study. PLoS One. 2011;6:e19987.

13. Hamdy S, Aziz Q, Rothwell JC, et al. Explaining oropharyngeal dysphagia after unilateral hemispheric stroke. Lancet. 1997;350(9079): 686-692.

14. Hamdy S, Aziz Q, Rothwell JC, et al. Recovery of swallowing after dysphagic stroke relates to functional reorganization in the intact motor cortex. Gastroenterology. 1998;115(5):1104-1112.

15. Li S, Chen Q, Yu B, et al. Structural and functional changes mapped in the brains of amyotrophic lateral sclerosis patients with/without dysphagia: a pilot study. Amyotroph Lateral Scler. 2009;10(5-6):280-287.
16. Dziewas R, Teismann I, Suntrup S, et al. Cortical compensation associated with dysphagia caused by selective degeneration of bulbar motor neurons. Hum Brain Mapp. 2009;30(4):1352-1360.

17. Suntrup S, Teismann I, Bejer J, et al. Evidence for adaptive cortical changes in swallowing in Parkinson's disease. Brain. 2013;136(Pt 3): 726-738.

18. Yang CJ, Roh JL, Choi KH, et al. Pretreatment Dysphagia Inventory and videofluorographic swallowing study as prognostic indicators of early survival outcomes in head and neck cancer. Cancer. 2015;121(10): 1588-1598.

19. Jiang N, Zhang LJ, Li LY, Zhao Y, Eisele DW. Risk factors for late dysphagia after (chemo) radiotherapy for head and neck cancer: a systematic methodological review. Head Neck. Epub 2014 Dec 22.

20. van den Berg MG, Rutten H, Rasmussen-Conrad EL, et al. Nutritional status, food intake, and dysphagia in long-term survivors with head and neck cancer treated with chemoradiotherapy: a cross-sectional study. Head Neck. 2014;36(1):60-65.

21. Kern M, Bardan E, Arndorfer R, Hofmann C, Ren J, Shaker R. Comparison of upper esophageal sphincter opening in healthy asymptomatic young and elderly volunteers. Ann Otol Rhinol Laryngol. 1999;108(10): 982-989.

22. Shaker R, Kern M, Bardan E, et al. Augmentation of deglutitive upper esophageal sphincter opening in the elderly by exercise. Am J Physiol. 1997;272(6 Pt 1):G1518-G1522.

23. Shaker R, Easterling C, Kern M, et al. Rehabilitation of swallowing by exercise in tube-fed patients with pharyngeal dysphagia secondary to abnormal UES opening. Gastroenterology. 2002;122(5): 1314-1321.

24. Massey B. Manometry of the UES Including High-Resolution Manometry. In: Shaker R, Easterling C, Belafsky PC, Postma GN, editors. Manual of Diagnostic and Therapeutic Techniques for Disorders of Deglutition. New York: Springer Publishing; 2012:129-149.

25. Easterling $C$, Shaker R. UES opening muscle dysfunction. In: Shaker R, Belafsky PC, Postma GN, Easterling C, editors. Principles of Deglutition: A Multidisciplinary Text for Swallowing and its Disorders. New York: Springer Publishing; 2013:529-535.

26. Don Kim K, Lee HJ, Lee MH, Ryu HJ. Effects of neck exercises on swallowing function of patients with stroke. J Phys Ther Sci. 2015;27(4): 1005-1008.

27. Kahrilas PJ, Logemann JA, Krugler C, Flanagan E. Volitional augmentation of upper esophageal sphincter opening during swallowing. Am J Physiol. 1991;260(3 Pt 1):G450-G456.

28. Altman KW, Yu GP, Schaefer SD. Consequence of dysphagia in the hospitalized patient: impact on prognosis and hospital resources. Arch Otolaryngol Head Neck Surg. 2010;136(8):784-789.

29. Muhle P, Wirth R, Glahn J, Dziewas R. Schluckstörungen im Alter [Age-related changes in swallowing. Physiology and pathophysiology]. Nervenarzt. 2015;86(4):440-451. German.

30. Rofes L, Arreola V, Romea M, et al. Pathophysiology of oropharyngeal dysphagia in the frail elderly. Neurogastroenterol Motil. 2010;22(8): 851-858, e230.

31. Tracy JF, Logemann JA, Kahrilas PJ, Jacob P, Kobara M, Krugler C. Preliminary observations on the effects of age on oropharyngeal deglutition. Dysphagia. 1989;4(2):90-94.

32. Sonies BC, Ship JA, Baum BJ. Relationship between saliva production and oropharyngeal swallow in healthy, different-aged adults. Dysphagia. 1989;4(2):85-89.

33. Rogus-Pulia NM, Logemann JA. Effects of reduced saliva production on swallowing in patients with Sjogren's syndrome. Dysphagia. 2011; 26(3):295-303.

34. Feng X, Todd T, Lintzenich CR, et al. Aging-related geniohyoid muscle atrophy is related to aspiration status in healthy older adults. J Gerontol A Biol Sci Med Sci. 2013;68(7):853-860.

35. Butler SG, Stuart A, Leng X, et al. The relationship of aspiration status with tongue and handgrip strength in healthy older adults. J Gerontol A Biol Sci Med Sci. 2011;66(4):452-458. 
36. Cruz-Jentoft AJ, Baeyens JP, Bauer JM, et al. Sarcopenia: European consensus on definition and diagnosis: Report of the European Working Group on Sarcopenia in Older People. Age Ageing. 2010;39(4):412-423.

37. Landi F, Liperoti R, Fusco D, et al. Sarcopenia and mortality among older nursing home residents. J Am Med Dir Assoc. 2012;13(2):121-126.

38. Sokoloff LG, Pavlakovic R. Neuroleptic-induced dysphagia. Dysphagia. 1997;12(4):177-179.

39. Yang EJ, Kim KW, Lim JY, Paik NJ. Relationship between dysphagia and mild cognitive impairment in a community-based elderly cohort: the Korean longitudinal study on health and aging. J Am Geriatr Soc. 2014;62(1):40-46.

40. Martino R, Beaton D, Diamant NE. Using different perspectives to generate items for a new scale measuring medical outcomes of dysphagia (MOD). J Clin Epidemiol. 2009;62(5):518-526.

41. Simonetti A, Viasus D, Garcia-Vidal C, et al. Timing of antibiotic administration and outcomes of hospitalized patients with communityacquired and healthcare-associated pneumonia. Clin Microbiol Infect. 2012;18(11):1149-1155.

42. Garcia-Vidal C, Viasus D, Roset A, et al. Low incidence of multidrugresistant organisms in patients with healthcare-associated pneumonia requiring hospitalization. Clin Microbiol Infect. 2011;17(11):1659-1665.

43. Komiya K, Ishii H, Umeki K, et al. Impact of aspiration pneumonia in patients with community-acquired pneumonia and healthcare-associated pneumonia: a multicenter retrospective cohort study. Respirology. 2013;18(3):514-521.

44. Kwong JC, Howden BP, Charles PG. New aspirations: the debate on aspiration pneumonia treatment guidelines. Med J Aust. 2011;195(7): 380-381.

45. Komiya K, Ishii H, Kadota J. Healthcare-associated Pneumonia and Aspiration Pneumonia. Aging Dis. 2015;6(1):27-37.

46. Hibberd J, Fraser J, Chapman C, McQueen H, Wilson A. Can we use influencing factors to predict aspiration pneumonia in the United Kingdom? Multidiscip Respir Med. 2013;8(1):39.

47. Gomes GF, Pisani JC, Macedo ED, Campos AC. The nasogastric feeding tube as a risk factor for aspiration and aspiration pneumonia. Curr Opin Clin Nutr Metab Care. 2003;6(3):327-333.

48. DeLegge MH. Aspiration pneumonia: incidence, mortality, and at-risk populations. JPENJ Parenter Enteral Nutr. 2002;26(6 Suppl):S19-S24; discussion S24-S15.

49. Kalita M, Majewska K, Gradowska A, Karwowska K, Lawinski M. Food, mechanic and septic complications in patients enterally nutritioned in home conditions. Pol Przegl Chir. 2014;86(10):466-472.

50. Hu X, Yi ES, Ryu JH. Aspiration-related deaths in 57 consecutive patients: autopsy study. PloS One. 2014;9(7):e103795.

51. Mier L, Dreyfuss D, Darchy B, et al. Is penicillin G an adequate initial treatment for aspiration pneumonia? A prospective evaluation using a protected specimen brush and quantitative cultures. Intensive Care Med. 1993;19(5):279-284.

52. Mandell LA, Wunderink RG, Anzueto A, et al. Infectious Diseases Society of America/American Thoracic Society consensus guidelines on the management of community-acquired pneumonia in adults. Clin Infect Dis. 2007;44 Suppl 2:S27-S72.

53. O’Donoghue C, Iversen C, Duggan J, Power D, Fanning S, Kyne L. Polypharmacy is an independent risk factor for oropharyngeal isolation of gram-negative bacilli in older persons. J Am Geriatr Soc. 2012;60(1): 182-183.

54. El-Solh AA, Pietrantoni C, Bhat A, et al. Microbiology of severe aspiration pneumonia in institutionalized elderly. Am J Respir Crit Care Med. 2003;167(12):1650-1654.

55. Lanspa MJ, Jones BE, Brown SM, Dean NC. Mortality, morbidity, and disease severity of patients with aspiration pneumonia. J Hosp Med. 2013;8(2):83-90.

56. Lanspa MJ, Peyrani P, Wiemken T, Wilson EL, Ramirez JA, Dean NC Characteristics associated with clinician diagnosis of aspiration pneumonia: a descriptive study of afflicted patients and their outcomes. J Hosp Med. 2015;10(2):90-96.
57. Falcone M, Blasi F, Menichetti F, Pea F, Violi F. Pneumonia in frail older patients: an up to date. Intern Emerg Med. 2012;7(5):415-424.

58. Kaiser MJ, Bauer JM, Ramsch C, et al. Frequency of malnutrition in older adults: a multinational perspective using the mini nutritional assessment. J Am Geriatr Soc. 2010;58(9):1734-1738.

59. Serra-Prat M, Palomera M, Gomez C, et al. Oropharyngeal dysphagia as a risk factor for malnutrition and lower respiratory tract infection in independently living older persons: a population-based prospective study. Age Ageing. 2012;41(3):376-381.

60. Valentini L, Schindler K, Schlaffer R, et al. The first nutrition Day in nursing homes: participation may improve malnutrition awareness. Clin Nutr. 2009;28(2):109-116.

61. Carrion S, Cabre M, Monteis R, et al. Oropharyngeal dysphagia is a prevalent risk factor for malnutrition in a cohort of older patients admitted with an acute disease to a general hospital. Clin Nutr. 2015;34(3): 436-442.

62. Poisson P, Laffond T, Campos S, Dupuis V, Bourdel-Marchasson I. Relationships between oral health, dysphagia and undernutrition in hospitalised elderly patients. Gerodontology. Epub 2014 Mar 11.

63. Foley NC, Salter KL, Robertson J, Teasell RW, Woodbury MG. Which reported estimate of the prevalence of malnutrition after stroke is valid? Stroke. 2009;40(3):e66-e74.

64. Davalos A, Ricart W, Gonzalez-Huix F, et al. Effect of malnutrition after acute stroke on clinical outcome. Stroke. 1996;27(6):1028-1032.

65. Finestone HM, Greene-Finestone LS, Wilson ES, Teasell RW. Prolonged length of stay and reduced functional improvement rate in malnourished stroke rehabilitation patients. Arch Phys Med Rehabil. 1996;77(4):340-345.

66. FOOD Trial Collaboration. Poor nutritional status on admission predicts poor outcomes after stroke: observational data from the FOOD trial. Stroke. 2003;34(6):1450-1456.

67. Davis JP, Wong AA, Schluter PJ, Henderson RD, O’Sullivan JD, Read SJ. Impact of premorbid undernutrition on outcome in stroke patients. Stroke. 2004;35(8):1930-1934.

68. Gariballa SE, Parker SG, Taub N, Castleden CM. Influence of nutritional status on clinical outcome after acute stroke. Am J Clin Nutr. 1998; 68(2):275-281.

69. Martino R, Foley N, Bhogal S, Diamant N, Speechley M, Teasell R. Dysphagia after stroke: incidence, diagnosis, and pulmonary complications. Stroke. 2005;36(12):2756-2763.

70. Yoo SH, Kim JS, Kwon SU, Yun SC, Koh JY, Kang DW. Undernutrition as a predictor of poor clinical outcomes in acute ischemic stroke patients. Arch Neurol. 2008;65(1):39-43.

71. Rofes L, Arreola V, Almirall J, et al. Diagnosis and management of oropharyngeal Dysphagia and its nutritional and respiratory complications in the elderly. Gastroenterol Res Pract. 2011;2011. pii:818979.

72. Wright L, Cotter D, Hickson M, Frost G. Comparison of energy and protein intakes of older people consuming a texture modified diet with a normal hospital diet. J Hum Nutr Diet. 2005;18(3):213-219.

73. Bannerman E, McDermott K. Dietary and fluid intakes of older adults in care homes requiring a texture modified diet: the role of snacks. J Am Med Dir Assoc. 2011;12(3):234-239.

74. Volkert D, Berner YN, Berry E, et al. ESPEN Guidelines on Enteral Nutrition: Geriatrics. Clin Nutr. 2006;25(2):330-360.

75. Wirth R, Smoliner C, Jager M, et al. Guideline clinical nutrition in patients with stroke. Exp Transl Stroke Med. 2013;5(1):14.

76. McCullough GH MR. Clinical evaluation of patients with dysphagia: Importance of history taking and physical exam. Manual of diagnostic and therapeutic techniques for disorders of deglutition. New York: Springer; 2013:11-30.

77. Martino R, Silver F, Teasell R, et al. The Toronto Bedside Swallowing Screening Test (TOR-BSST): development and validation of a dysphagia screening tool for patients with stroke. Stroke. 2009;40(2):555-561.

78. Streiner DL. Diagnosing tests: using and misusing diagnostic and screening tests. J Pers Assess. 2003;81(3):209-219. 
79. Martino R, Pron G, Diamant NE. Oropharyngeal dysphagia: surveying practice patterns of the speech-language pathologist. Dysphagia. 2004;19(3):165-176.

80. Hinchey JA, Shephard T, Furie K, et al. Formal dysphagia screening protocols prevent pneumonia. Stroke. 2005;36(9):1972-1976.

81. Jauch EC, Saver JL, Adams HP Jr, et al. Guidelines for the early management of patients with acute ischemic stroke: a guideline for healthcare professionals from the American Heart Association/ American Stroke Association. Stroke. 2013;44(3):870-947.

82. No authors listed. National clinical guidelines for stroke: a concise update. Clin Med. 2002;2(3):231-233.

83. Australian National Stroke Foundation. Clinical guidelines for acute stroke management. National Stroke Foundation; 2007. Available from: https://www.nhmrc.gov.au/_files_nhmrc/publications/attachments/cp109.pdf. Accessed November 18, 2015.

84. Casaubon LK, Suddes M on behalf of the Acute Stroke Best Practices Writing Group 2013. Acute inpatient stroke care. Canadian best practice recommendations for stroke care; 2013. Available from: http://www.strokebestpractices.ca/wp-content/uploads/2010/10/ Ch4_SBP2013_Acute-Inpatient-Care_22MAY13_EN_FINAL4.pdf. Accessed November 18, 2015.

85. Whiting PF, Rutjes AW, Westwood ME, et al. QUADAS-2: a revised tool for the quality assessment of diagnostic accuracy studies. Ann Intern Med. 2011;155(8):529-536

86. Schepp SK, Tirschwell DL, Miller RM, Longstreth WT Jr. Swallowing screens after acute stroke: a systematic review. Stroke. 2012;43(3): 869-871.

87. Edmiaston J, Connor LT, Loehr L, Nassief A. Validation of a dysphagia screening tool in acute stroke patients. Am J Crit Care. 2010;19(4): 357-364.

88. Martino R, Flowers HL, Shaw SM, Diamant NE. A systematic review of current clinical and instrumental swallowing assessment methods. Curr Phys Med Rehabil Rep. 2013;1:267-279.

89. Rosenbek JC, Robbins JA, Roecker EB, Coyle JL, Wood JL. A penetration-aspiration scale. Dysphagia. 1996;11(2):93-98.

90. Rofes L, Arreola V, Mukherjee R, Swanson J, Clave P. The effects of a xanthan gum-based thickener on the swallowing function of patients with dysphagia. Aliment Pharmacol Ther. 2014;39(10):1169-1179.

91. Langmore SE, Schatz K, Olsen N. Fiberoptic endoscopic examination of swallowing safety: a new procedure. Dysphagia. 1988;2(4): 216-219.

92. Langmore SE, Schatz K, Olson N. Endoscopic and videofluoroscopic evaluations of swallowing and aspiration. Ann Otol Rhinol Laryngol. 1991;100(8):678-681.

93. Langmore SE. Endoscopic Evaluation and Treatment of Swallowing Disorders. New York: Thieme; 2001.

94. Langmore SE, Murray J. Flexible Endoscopic Evaluation of Swallowing. In: Shaker R, Belafsky PC, Postma GN, Easterling C, editors. Principles of Deglutition: A Multidisciplinary Text for Swallowing and its Disorder. New York: Springer; 2012:85-101.

95. Langmore SE. Flexible endoscopic evaluation of swallowing. In: Johnson AF, Jacobson BJ, editors. Medical Speech-Language Pathology. New York: Thieme; 2015:148-157.

96. Manor Y, Mootanah R, Freud D, Giladi N, Cohen JT. Video-assisted swallowing therapy for patients with Parkinson's disease. Parkinsonism Relat Disord. 2013;19(2):207-211.

97. Butler SG, Clark H, Baginski SG, Todd JT, Lintzenich C, Leng X. Computed tomography pulmonary findings in healthy older adult aspirators versus nonaspirators. Laryngoscope. 2014;124(2):494-497.

98. Murray J, Langmore SE, Ginsberg S, Dostie A. The significance of accumulated oropharyngeal secretions and swallowing frequency in predicting aspiration. Dysphagia. 1996;11(2):99-103.

99. Takahashi N, Kikutani T, Tamura F, Groher M, Kuboki T. Videoendoscopic assessment of swallowing function to predict the future incidence of pneumonia of the elderly. J Oral Rehabil. 2012;39(6): $429-437$.
100. Huckabee ML. Biofeedback-Monitoring zur Effektivierung der Schluckrehabiliation [Biofeedback-monitoring for enhancement of dysphagia rehabilitation]. In: Stanschus S, editor. Methoden der Klinischen Dysphagiologie [Methods Clinical Dysphagiologie]. Idstein; 2002:9-38. German.

101. Rosenbek J. Historical, present and future consideration on clinical dysphagiology. Dysphagieforum. 2013;3(1):51-54. Available from: http://www.schulz-kirchner.de/filesl/df1_2013.pdf. Accessed December 14, 2015.

102. Titsworth WL, Abram J, Fullerton A, et al. Prospective quality initiative to maximize dysphagia screening reduces hospital-acquired pneumonia prevalence in patients with stroke. Stroke. 2013;44(11): 3154-3160.

103. Gandolfi M, Smania N, Bisoffi G, Squaquara T, Zuccher P, Mazzucco S. Improving post-stroke dysphagia outcomes through a standardized and multidisciplinary protocol: an exploratory cohort study. Dysphagia. 2014;29(6):704-712.

104. Carnaby G, Hankey GJ, Pizzi J. Behavioural intervention for dysphagia in acute stroke: a randomised controlled trial. Lancet Neurol. 2006;5(1):31-37.

105. Bartholome G. Schluckstörungen Neurorehabilitation. Berlin: Blachwell; 1999.

106. Cichero JA, Steele C, Duivestein J, et al. The Need for International Terminology and Definitions for Texture-Modified Foods and Thickened Liquids Used in Dysphagia Management: Foundations of a Global Initiative. Curr Phys Med Rehabil Rep. 2013;1:280-291.

107. Wheeler-Hegland K, Ashford J, Frymark T, et al. Evidence-based systematic review: oropharyngeal dysphagia behavioral treatments. Part II - impact of dysphagia treatment on normal swallow function. J Rehabil Res Dev. 2009;46(2):185-194.

108. Drulia TC, Ludlow CL. Relative Efficacy of Swallowing versus Nonswallowing Tasks in Dysphagia Rehabilitation: Current Evidence and Future Directions. Curr Phys Med Rehabil Rep. 2013;1(4):242-256.

109. Langmore SE, Pisegna JM. Efficacy of exercises to rehabilitate dysphagia: a critique of the literature. Int J Speech Lang Pathol. 2015; 17(3):222-229.

110. Speyer R, Baijens L, Heijnen M, Zwijnenberg I. Effects of therapy in oropharyngeal dysphagia by speech and language therapists: a systematic review. Dysphagia. 2010;25(1):40-65.

111. McHorney CA, Bricker DE, Kramer AE, et al. The SWAL-QOL outcomes tool for oropharyngeal dysphagia in adults: I. Conceptual foundation and item development. Dysphagia. 2000;15(3):115-121.

112. Cook IJ, Kahrilas PJ. AGA technical review on management of oropharyngeal dysphagia. Gastroenterology. 1999;116(2):455-478.

113. Andersen UT, Beck AM, Kjaersgaard A, Hansen T, Poulson I. Systematic review and evidence based recommendations on texture modified foods and thickened fluids for adults with oropharyngeal dysphagia. e-SPEN Journal. 2013;8(4):e127-e134.

114. Keller H, Chambers L, Niezgoda H, Duizer L. Issues associated with the use of modified texture foods. J Nutr Health Aging. 2012; 16(3):195-200.

115. Cichero JA, Murdoch BE, editors. Dysphagia, foundation, theory and practice. John Wiley \& Sons; 2006.

116. Logemann JA, Pauloski BR, Colangelo L, Lazarus C, Fujiu M, Kahrilas PJ. Effects of a sour bolus on oropharyngeal swallowing measures in patients with neurogenic dysphagia. J Speech Hear Res. 1995;38(3):556-563.

117. Rosenbek JC, Roecker EB, Wood JL, Robbins J. Thermal application reduces the duration of stage transition in dysphagia after stroke. Dysphagia. 1996;11(4):225-233.

118. Kaatzke-McDonald MN, Post E, Davis PJ. The effects of cold, touch, and chemical stimulation of the anterior faucial pillar on human swallowing. Dysphagia. 1996;11(3):198-206.

119. de Lama Lazzara G, Lazarus C, Logemann JA. Impact of thermal stimulation on the triggering of the swallowing reflex. Dysphagia. 1986;1(2):73-77. 
120. Rosenbek JC, Robbins J, Willford WO, et al. Comparing treatment intensities of tactile-thermal application. Dysphagia. 1998; 13(1):1-9.

121. Power ML, Fraser CH, Hobson A, et al. Evaluating oral stimulation as a treatment for dysphagia after stroke. Dysphagia. 2006;21(1): 49-55.

122. Freed ML, Freed L, Chatburn RL, Christian M. Electrical stimulation for swallowing disorders caused by stroke. Respir Care. 2001;46(5): 466-474.

123. Rofes L, Arreola V, Martin A, Clave P. Natural capsaicinoids improve swallow response in older patients with oropharyngeal dysphagia. Gut. 2013;62(9):1280-1287.

124. Fraser C, Power M, Hamdy S, et al. Driving plasticity in human adult motor cortex is associated with improved motor function after brain injury. Neuron. 2002;34(5):831-840.

125. Jayasekeran V, Singh S, Tyrrell P, et al. Adjunctive functional pharyngeal electrical stimulation reverses swallowing disability after brain lesions. Gastroenterology. 2010;138(5):1737-1746.

126. Michou E, Hamdy S. Cortical input in control of swallowing. Curr Opin Otolaryngol Head Neck Surg. 2009;17(3):166-171.

127. Lisanby SH, Kinnunen LH, Crupain MJ. Applications of TMS to therapy in psychiatry. J Clin Neurophysiol. 2002;19(4):344-360.

128. Khedr EM, Abo-Elfetoh N, Rothwell JC. Treatment of post-stroke dysphagia with repetitive transcranial magnetic stimulation. Acta Neurol Scand. 2009;119(3):155-161.

129. Verin E, Leroi AM. Poststroke dysphagia rehabilitation by repetitive transcranial magnetic stimulation: a noncontrolled pilot study. Dysphagia. 2009;24(2):204-210.

130. Khedr EM, Abo-Elfetoh N. Therapeutic role of rTMS on recovery of dysphagia in patients with lateral medullary syndrome and brainstem infarction. J Neurol Neurosurg Psychiatry. 2010;81(5): 495-499.

131. Adeyemo BO, Simis M, Macea DD, Fregni F. Systematic review of parameters of stimulation, clinical trial design characteristics, and motor outcomes in non-invasive brain stimulation in stroke. Front Psychiatry. 2012;3:88.

132. Jefferson S, Mistry S, Singh S, Rothwell J, Hamdy S. Characterizing the application of transcranial direct current stimulation in human pharyngeal motor cortex. Am J Physiol Gastrointest Liver Physiol 2009;297(6):G1035-G1040.

133. Shigematsu T, Fujishima I, Ohno K. Transcranial direct current stimulation improves swallowing function in stroke patients. Neurorehabil Neural Repair. 2013;27(4):363-369.

134. Kumar S, Wagner CW, Frayne C, et al. Noninvasive brain stimulation may improve stroke-related dysphagia: a pilot study. Stroke. 2011; 42(4):1035-1040.

135. Yang EJ, Baek SR, Shin J, et al. Effects of transcranial direct current stimulation (tDCS) on post-stroke dysphagia. Restor Neurol Neurosci. 2012;30(4):303-311.

136. Volkert D, Bauer JM, Frühwald T, et al. Leitlinie der Deutschen Gesellschaft für Ernährungsmedizin (DGEM) in Zusammenarbeit mir der GESEKES, der AKE und DGG: Kinische Ernährung in der Geriatrie [Guideline of the German Society for Nutritional Medicine (DGEM) in cooporation with the GESKES, the AKE and the DGG: Clinical Nutrition in Geriatrics]. Aktuel Ernährungsmed. 2013;38:1-48. German.

137. Kudsk KA, Croce MA, Fabian TC, et al. Enteral versus parenteral feeding. Effects on septic morbidity after blunt and penetrating abdominal trauma. Ann Surg. 1992;215(5):503-511; discussion 511-513.

138. Moore FA, Feliciano DV, Andrassy RJ, et al. Early enteral feeding, compared with parenteral, reduces postoperative septic complications. The results of a meta-analysis. Ann Surg. 1992;216(2):172-183.

139. Gomes CA Jr, Lustosa SA, Matos D, Andriolo RB, Waisberg DR, Waisberg J. Percutaneous endoscopic gastrostomy versus nasogastric tube feeding for adults with swallowing disturbances. Cochrane Database Syst Rev. 2012;3:CD008096.
140. Jaafar MH, Mahadeva S, Morgan K, Tan MP. Percutaneous endoscopic gastrostomy versus nasogastric feeding in older individuals with nonstroke dysphagia: a systematic review. J Nutr Health Aging. 2015; 19(2):190-197.

141. Wang J, Liu M, Liu C, Ye Y, Huang G. Percutaneous endoscopic gastrostomy versus nasogastric tube feeding for patients with head and neck cancer: a systematic review. J Radiat Res. 2014;55(3):559-567.

142. Dennis MS, Lewis SC, Warlow C, FOOD Trial Collaboration. Effect of timing and method of enteral tube feeding for dysphagic stroke patients (FOOD): a multicentre randomised controlled trial. Lancet. 2005;365(9461):764-772.

143. Dennis M, Lewis S, Cranswick G, Forbes J, FOOD Trial Collaboration. FOOD: a multicentre randomised trial evaluating feeding policies in patients admitted to hospital with a recent stroke. Health Technol Assess. 2006;10(2):iii-iv, ix-x, 1-120.

144. Geeganage C, Beavan J, Ellender S, Bath PM. Interventions for dysphagia and nutritional support in acute and subacute stroke. Cochrane Database Syst Rev. 2012;10:CD000323.

145. Bechtold ML, Nguyen DL, Palmer LB, Kiraly LN, Martindale RG, McClave SA. Nasal bridles for securing nasoenteric tubes: a metaanalysis. Nutr Clin Pract. 2014;29(5):667-671.

146. Crisan D, Shaban A, Boehme A, et al. Predictors of recovery of functional swallow after gastrostomy tube placement for Dysphagia in stroke patients after inpatient rehabilitation: a pilot study. Ann Rehabil Med. 2014;38(4):467-475.

147. Sheard JM, Ash S, Silburn PA, Kerr GK. Prevalence of malnutrition in Parkinson's disease: a systematic review. Nutr Rev. 2011;69(9): 520-532.

148. Sheard JM, Ash S, Mellick GD, Silburn PA, Kerr GK. Markers of disease severity are associated with malnutrition in Parkinson's disease. PloS One. 2013;8(3):e57986.

149. Livesay S, Ruppert SD. Pneumonia and encephalopathy in a patient with progressing Parkinson's disease and dementia. Crit Care Nurs $Q$. 2012;35(2):160-172

150. Nyholm D. Duodopa ${ }^{\circledR}$ treatment for advanced Parkinson's disease: a review of efficacy and safety. Parkinsonism Relat Disord. 2012;18(8): 916-929.

151. Langmore SE, Kasarskis EJ, Manca ML, Olney RK. Enteral tube feeding for amyotrophic lateral sclerosis/motor neuron disease. Cochrane Database Syst Rev. 2006(4):CD004030.

152. Priefer BA, Robbins J. Eating changes in mild-stage Alzheimer's disease: a pilot study. Dysphagia. 1997;12(4):212-221.

153. Humbert IA, McLaren DG, Kosmatka K, et al. Early deficits in cortical control of swallowing in Alzheimer's disease. J Alzheimers Dis. 2010;19(4):1185-1197.

154. Suh MK, Kim H, Na DL. Dysphagia in patients with dementia: Alzheimer versus vascular. Alzheimer Dis Assoc Disord. 2009;23(2): $178-184$.

155. Levine R, Robbins JA, Maser A. Periventricular white matter changes and oropharyngeal swallowing in normal individuals. Dysphagia. 1992;7(3):142-147.

156. Londos E, Hanxsson O, Alm Hirsch I, Janneskog A, Bulow M, Palmqvist $\mathrm{S}$. Dysphagia in Lewy body dementia - a clinical observational study of swallowing function by videofluoroscopic examination. BMC Neurol. 2013;13:140.

157. Langmore SE, Olney RK, Lomen-Hoerth C, Miller BL. Dysphagia in patients with frontotemporal lobar dementia. Arch Neurol. 2007;64(1): 58-62.

158. Bautmans I, Demarteau J, Cruts B, Lemper JC, Mets T. Dysphagia in elderly nursing home residents with severe cognitive impairment can be attenuated by cervical spine mobilization. $J$ Rehabil Med. 2008;40(9):755-760.

159. Logemann JA, Gensler G, Robbins J, et al. A randomized study of three interventions for aspiration of thin liquids in patients with dementia or Parkinson's disease. J Speech Lang Hear Res. 2008;51(1): 173-183. 
160. Robbins J, Gensler G, Hind J, et al. Comparison of 2 interventions for liquid aspiration on pneumonia incidence: a randomized trial. Ann Intern Med. 2008;148(7):509-518.

161. Rosler A, Pfeil S, Lessmann H, Hoder J, Befahr A, RentelnKruse WV. Dysphagia in Dementia: Influence of Dementia Severity and Food Texture on the Prevalence of Aspiration and Latency to Swallow in Hospitalized Geriatric Patients. J Am Med Dir Assoc. 2015;16(8):697-701.

162. Pringsheim T, Jette N, Frolkis A, Steeves TD. The prevalence of Parkinson's disease: a systematic review and meta-analysis. Mov Disord. 2014;29(13):1583-1590.

163. Coelho M, Marti MJ, Tolosa E, et al. Late-stage Parkinson's disease: the Barcelona and Lisbon cohort. J Neurol. 2010;257(9):1524-1532.

164. Manor Y, Giladi N, Cohen A, Fliss DM, Cohen JT. Validation of a swallowing disturbance questionnaire for detecting dysphagia in patients with Parkinson's disease. Mov Disord. 2007;22(13):1917-1921.

165. Muller J, Wenning GK, Verny M, et al. Progression of dysarthria and dysphagia in postmortem-confirmed parkinsonian disorders. Arch Neurol. 2001;58(2):259-264.

166. Lam K, Lam FK, Lau KK, et al. Simple clinical tests may predict severe oropharyngeal dysphagia in Parkinson's disease. Mov Disord. 2007;22(5):640-644.

167. Cereda E, Cilia R, Klersy C, et al. Swallowing disturbances in Parkinson's disease: a multivariate analysis of contributing factors. Parkinsonism Relat Disord. 2014;20(12):1382-1387.
168. Simons JA, Fietzek UM, Waldmann A, Warnecke T, Schuster T, Ceballos-Baumann AO. Development and validation of a new screening questionnaire for dysphagia in early stages of Parkinson's disease. Parkinsonism Relat Disord. 2014;20(9):992-998.

169. Kalf H, de Swart B, Bonnier-Baars M, Kanters J, Hofman M, Kocken J, Miltenburg M, Bloem B, Munecke M. Guideline for speech-language therapy in Parkinson's disease. Nijmegen, the Netherlands: NVLF, Woerden 2008/Lemma Publishers; 2008.

170. Warnecke T. Parkinsonbedingte Dysphagien. [Parkinson's disease related dysphagia]. Nervenheilkunde. 2014;33(1-2):31-35. German.

171. El Sharkawi A, Ramig L, Logemann JA, et al. Swallowing and voice effects of Lee Silverman Voice Treatment (LSVT): a pilot study. J Neurol Neurosurg Psychiatry. 2002;72(1):31-36.

172. Troche MS, Okun MS, Rosenbek JC, et al. Aspiration and swallowing in Parkinson disease and rehabilitation with EMST: a randomized trial. Neurology. 2010;75(21):1912-1919.

173. Warnecke T, Oelenberg S, Teismann I, et al. Endoscopic characteristics and levodopa responsiveness of swallowing function in progressive supranuclear palsy. Mov Disord. 2010;25(9):1239-1245.

174. Warnecke T, Hamacher C, Oelenberg S, Dziewas R. Off and on state assessment of swallowing function in Parkinson's disease. Parkinsonism Relat Disord. 2014;20(9):1033-1034.
Clinical Interventions in Aging

\section{Publish your work in this journal}

Clinical Interventions in Aging is an international, peer-reviewed journal focusing on evidence-based reports on the value or lack thereof of treatments intended to prevent or delay the onset of maladaptive correlates of aging in human beings. This journal is indexed on PubMed Central, MedLine,

\section{Dovepress}

CAS, Scopus and the Elsevier Bibliographic databases. The manuscript management system is completely online and includes a very quick and fair peer-review system, which is all easy to use. Visit http://www.dovepress. com/testimonials.php to read real quotes from published authors. 